Manuscript Number:

Title: Large mammal diets and paleoecology across the Oldowan-Acheulean transition at Olduvai Gorge, Tanzania from stable isotope and tooth wear analyses

Article Type: SI: Oldowan-Acheulean

Keywords: intratooth isotope profile, mesowear, microwear, Bed II, paleodiet, herbivore

Corresponding Author: Dr. Kevin Uno, PhD

Corresponding Author's Institution: Lamont Doherty Earth Observatory of Columbia University

First Author: Kevin Uno, PhD

Order of Authors: Kevin Uno, PhD; Florent Rivals, PhD; Faysal Bibi, PhD; Michael Pante, PhD; Jackson Njau, PhD; Ignacio de la Torre, PhD

Abstract: The well-dated Pleistocene sediments at Olduvai Gorge have yielded an incredibly rich record of hominin fossils, stone tools, and vertebrate faunal remains that taken together, provide insight to hominin behavior and paleoecology. Since 2009, the Olduvai Geochronology and Archeology Project has undertaken extensive excavations in Bed II that have yielded a large collection of early Pleistocene stone tools and fossils. The strata of Lower, Middle and Upper Bed II at Olduvai Gorge capture the critical transition from Oldowan to Acheulean technology and therefore provide an opportunity to explore the possible role of biotic and abiotic change during the transition. Here, we analyze newly discovered and existing fossil teeth from Bed II sites using stable isotope and tooth wear methods to investigate the diets of large mammals. We reconstruct the dietary ecology of Bed II mammals and evaluate whether vegetation or hydroclimate shifts are associated with the technological change. Combined isotope and tooth wear data suggest most mammals were C4 grazers or mixed feeders. Carbon isotope data from bulk enamel samples indicate that 77\% of Bed II large mammals analyzed ( $\mathrm{n}=141)$ had diets comprised of mostly C4 vegetation (> 75\% of diet), $18 \%$ had mixed C3C4 diets, and 5\% had mostly C3 diets (< 25\% C4). Carbon isotope data indicate a decrease in the number of mixed and C3 feeders in interval IIB. Tooth mesowear generally indicate an increase of the abrasiveness of the diet between intervals IIA and IIB, probably related to an increase in grazing. Microwear data indicates more abrasive diets in interval IIA suggesting stronger seasonal differences at the time of death. This is also supported by the intratooth isotope profiles from Equus oldowayensis molars which suggest a possible decrease in seasonality across the transition. Neither stable isotope nor tooth wear analyses indicate major vegetation or hydrological change across the oldowan-Acheulean transition. 


\title{
Large mammal diets and paleoecology across the Oldowan-Acheulean transition at Olduvai Gorge, Tanzania from stable isotope and tooth wear analyses
}

Kevin T. Uno ${ }^{1}$, Florent Rivals ${ }^{2,3,4}$, Faysal Bibi ${ }^{5}$, Michael Pante ${ }^{6}$, Jackson Njau ${ }^{7}$, Ignacio de la Torre $^{8}$

Author affiliations:

1) Lamont-Doherty Earth Observatory of Columbia University, Palisades, New York, USA

2) Institució Catalana de Recerca i Estudis Avançats (ICREA), Pg. Lluís Companys 23, 08010 Barcelona, Spain

3) Institut Català de Paleoecologia Humana i Evolució Social (IPHES), Zona Educacional 4, Campus Sescelades URV (Edifici W3), 43007 Tarragona, Spain

4) Area de Prehistoria, Universitat Rovira i Virgili (URV), Avinguda de Catalunya 35, 43002 Tarragona, Spain

5) Museum für Naturkunde, Leibniz-Institut für Evolutions- und Biodiversitätsforschung, Berlin, Germany

6) Department of Anthropology, Colorado State University, 1787 Campus Delivery, Fort Collins, CO, 80523, USA

7) Department of Geological Sciences, Indiana University, 1001 E Tenth Street, Bloomington, IN 47405, USA

8) Institute of Archaeology, University College London, 31-34 Gordon Square, London WC1H 0PY, UK

Author email addresses:

kevinuno@1deo.columbia.edu, florent.rivals@icrea.cat, faysal.bibi@mfn-berlin.de, Michael.Pante@colostate.edu, jknjau@indiana.edu, i.torre@ucl.ac.uk

Key words: intratooth isotope profile, mesowear, microwear, Bed II, paleodiet, herbivore

\begin{abstract}
The well-dated Pleistocene sediments at Olduvai Gorge have yielded an incredibly rich record of hominin fossils, stone tools, and vertebrate faunal remains that taken together, provide insight to hominin behavior and paleoecology. Since 2009, the Olduvai Geochronology and Archeology
\end{abstract}


Project has undertaken extensive excavations in Bed II that have yielded a large collection of early Pleistocene stone tools and fossils. The strata of Lower, Middle and Upper Bed II at Olduvai Gorge capture the critical transition from Oldowan to Acheulean technology and therefore provide an opportunity to explore the possible role of biotic and abiotic change during the transition. Here, we analyze newly discovered and existing fossil teeth from Bed II sites using stable isotope and tooth wear methods to investigate the diets of large mammals. We reconstruct the dietary ecology of Bed II mammals and evaluate whether vegetation or hydroclimate shifts are associated with the technological change. Combined isotope and tooth wear data suggest most mammals were $\mathrm{C}_{4}$ grazers or mixed feeders. Carbon isotope data from bulk enamel samples indicate that $77 \%$ of Bed II large mammals analyzed $(n=141)$ had diets comprised of mostly $\mathrm{C}_{4}$ vegetation ( $\geq 75 \%$ of diet), $\sim 18 \%$ had mixed $\mathrm{C}_{3} \mathrm{C}_{4}$ diets, and $5 \%$ had mostly $\mathrm{C}_{3}$ diets $\left(\leq 25 \% \mathrm{C}_{4}\right)$. Carbon isotope data indicate a decrease in the number of mixed and $\mathrm{C}_{3}$ feeders in interval IIB. Tooth mesowear generally indicate an increase of the abrasiveness of the diet between intervals IIA and IIB, probably related to an increase in grazing. Microwear data indicates more abrasive diets in interval IIA suggesting stronger seasonal differences at the time of death. This is also supported by the intratooth isotope profiles from Equus oldowayensis molars which suggest a possible decrease in seasonality across the transition. Neither stable isotope nor tooth wear analyses indicate major vegetation or hydrological change across the Oldowan-Acheulean transition.

\section{Introduction}

Olduvai Gorge contains one of the richest early Pleistocene records of stone tools and humanmodified bones in eastern Africa, a record that provides evidence of hominin behavior and their interactions with other mammals on the landscape. Vertebrate fossils in the gorge were first 
studied by Hans Reck's team over 100 years ago, then by Mary and Louis Leakey whose artifact and hominin fossil discoveries became world-renowned (Leakey, 1959; Leakey et al., 1964; Leakey, 1971). The pioneering paleoanthropological work by Mary Leakey and colleagues was placed in a geological framework by Richard Hay, who defined the stratigraphy of Olduvai Gorge (Hay, 1963) based on the original work of Hans Reck $(1928,1951)$. A more complete study of the geology of Olduvai, with a focus on the stratigraphy, was published later by Hay (1976). The Bed II stratigraphic framework established by Hay is revised by Stanistreet et al. (this volume). Much effort has gone into determining the ages of the fossils and artifacts from Bed I and Bed II sites throughout the gorge using combined radiometric dating (Curtis and Hay, 1972; Deino, 2012; Manega, 1993) and correlation of volcanic tuffs when direct dating is not possible (Habermann et al., 2016a; McHenry, 2012; McHenry et al., 2016).

One exceptional feature of Olduvai Gorge is that it is one of only a handful of places known to date that captures the Oldowan-Acheulean transition (Leakey, 1971). Renewed excavations at Bed II sites by the Olduvai Geochronology and Archeology Project (OGAP), especially at the Henrietta Wilfrida Korongo East East site (HWK EE; Figure 1), has produced more than 18,000 artifacts and nearly 30,000 fossils (de la Torre, this volume; New excavations at the HWK EE site) that when combined with other, younger Bed II sites (e.g., EF-HR, MNK, FC East and FC West, HWK E-Tembo and FLK West), shed new light on the OldowanAcheulean transition, tool use, and hominin-carnivore interactions from 1.7 to $1.6 \mathrm{Ma}$ (Pante et al., this volume). Reconstructing the paleoenvironment at Olduvai Gorge is essential to understanding the role of environmental change during this major archeological transition.

A multitude of approaches to reconstructing paleoenvironments have produced a wealth of information about the flora and fauna of Olduvai Gorge, especially for Bed I. These include vertebrate paleontology (e.g., Gentry and Gentry, 1978; Kovarovic et al., 2013; Plummer and 
Bishop, 1994)(Bibi et al., this volume), analysis of plant macro- and microfossils (Albert et al., 2015a; Albert and Bamford, 2012; Bamford, 2012; Bamford et al., 2006; Bamford et al., 2008; Barboni et al., 2010; Bonnefille, 1984), paleopedology (Ashley et al., 2014), and isotopic studies of soil carbonates and organic matter (Cerling and Hay, 1986; Sikes, 1994; Sikes and Ashley, 2007), mammalian teeth (Van der Merwe, 2013), and plant biomarkers (Magill et al., 2016; Magill et al., 2013a, b). Three main conclusions about Olduvai Gorge based on the many paleoenvironmental studies are that first, the region has long been an arid to semi-arid ecosystem (Bonnefille, 1984). Second, there is evidence for a highly variable landscape both spatially (Barboni et al., 2010; Magill et al., 2016) that includes more mesic wetland areas (e.g., lake margins) and groundwater spring systems and temporally, which has been well documented in Bed I (Bamford, 2012; Magill et al., 2013b). Third, there is an overall shift towards more arid conditions between $\sim 1.9 \mathrm{Ma}$ and the present based carbon and oxygen isotope ratios in pedogenic carbonates (Cerling and Hay, 1986; Sikes and Ashley, 2007) and during Bed II times based on the avian fossil record (Prassack et al., this volume).

Figure 1 about here

Fossil teeth of large herbivores can be used to reconstruct past environments based on their morphology, microwear texture, and geochemistry. Both stable isotope and tooth wear methods are commonly used for paleodietary and paleovegetation reconstructions, yet these powerful and well-established methods have not yet been applied to Bed II fossil teeth. The recent excavation of new fossil teeth by the OGAP team, combined with the existing teeth collected by Mary Leakey's team in the early 1970's, present an opportunity to reconstruct the paleoenvironment and mammal diets during the Oldowan-Acheulean transition (see also Rivals 
et al., this volume). Here, we use stable isotope analysis and tooth wear methods from Bed II sites to evaluate diet, vegetation, and hydroclimate during the transition. Results from these independent approaches for reconstructing diet and vegetation are combined to provide a robust assessment of the paleoenvironment at the origin of the Acheulean at Olduvai Gorge.

\section{Materials and Methods}

\subsection{Teeth analyzed for stable isotopes, mesowear and microwear}

Fossil teeth sampled for stable isotope analysis come from the Leakey and OGAP research collections. A total of 141 fossil teeth were sampled from the HWK EE, FC East, FC West, MNK, FLK West, HWK E-Tembo, and EF-HR sites (Figure 1). Teeth represent a wide range of mammals, including Proboscidea (Elephantidae, Deinotheriidae), Perissodactyla (Rhinocerotidae, Equidae), Artiodactyla (Bovidae, Giraffidae, Hippopotamidae, Suidae), Carnivora (Hyaenidae), and Primates (Cercopithecidae) (see Table 1).

The sampling strategy for stable isotope and tooth wear analyses is designed to include as many taxa from the faunal assemblage and to capture the full dietary diversity. It is also designed to reflect relative faunal abundances observed in the faunal assemblage. For example, abundant taxa such as Alcelaphini and Equidae in Bed II at Olduvai are also the most abundant taxa in the isotope and tooth wear data sets. Where possible, at least 5 specimens from each clade were analyzed to represent the dietary breadth present. This is not always possible for rarer taxa, such as Deinotheriidae and Giraffa. In some cases, analyzed samples for very abundant taxa are underrepresented (e.g., Alcelaphini), and for rare taxa it is possible for them to be underor oversampled with respect to their relative abundance in the faunal assemblage.

Table 1 about here 
To evaluate whether the specimens sampled for isotope analysis represent the entire faunal assemblage, we calculate the coefficient of determination between the relative abundance of the number of individual specimens (NISP) from the OGAP fossil tooth database (Bibi et al., this volume) and that of the isotope data set. If the two datasets are similar, then community level interpretations of the isotope data can be applied to the NISP data set.

A second important consideration is fossil provenance. Patterson et al. (2017) demonstrate that Pleistocene paleontological and archeological sites have different faunal compositions for large mammals in the Turkana Basin. At Olduvai, where the archaeological deposits are thicker and therefore likely more palimpsest in nature, we consider the Bed II fauna as a combination of archeological and paleontological in provenance.

Most of the teeth (135 of 141) from these sites can be assigned to two stratigraphic intervals that span the Bed II subformations (Lower, Middle, and Upper), as defined by Hay (1976) (see also Stanistreet et al, this volume). The ages of the two intervals, denoted here as interval IIA and interval IIB, are based on associated radiometric ages of tephra layers. Sixtythree teeth recovered from HWK EE trenches, HWK E-Tembo, Trench 73 at FLK West, and Trench 36 and the Skull site at MNK are assigned an age of $\sim 1.7 \mathrm{Ma}$, based on the reported ages of 1.66 and 1.71 Ma of Tuff IIA by Manega (1993) and Curtis and Hay (1972), respectively. We follow the recommendation of Curtis and Hay and use only a single age (1.71 Ma) from Tuff IIA based on higher K content of that sample (KA 2320) relative to other dated Tuff IIA samples (Curtis and Hay, 1972). These trenches are all stratigraphically positioned between Tuff IIA and Tuff IIB, and are here included in what we term interval IIA. Seventy-two teeth come from between Tuff IIB and IIC, and are grouped within what we term interval IIB. Interval IIB teeth are assigned an age of $\sim 1.6 \mathrm{Ma}$ based on their proximity to the Bird Print Tuff (BPT), which lies 
just above Tuff IIB and has been geochemically correlated by McHenry (this issue) to the recently dated Tuff FLKWb, with a reported age of $1.664 \pm 0.019$ Ma (Diez-Martín et al., 2015) . Interval IIB includes fossil teeth from all FC East and West trenches, the MNK Main and T5 trenches, and HWK E-Tembo. Six teeth come from above Tuff IIC (IIC interval), which include 3 from EF-HR and 3 from FLK Trench 69. Tuff IIC is not dated. Tuff IID is dated around 1.48 Ma (Manega, 1993) or 1.34 Ma in age (Domínguez-Rodrigo et al., 2013).

The material studied for meso- and microwear was selected from all the specimens available in the collections from HWK EE, FC East, FC West, and MNK. We analyzed large herbivorous mammals among Proboscidea (Elephantidae, Deinotheriidae), Perissodactyla (Rhinocerotidae, Equidae), and Artiodactyla (Giraffidae, Hippopotamidae, Suidae, Bovidae). For Bovidae, where identification of isolated teeth to species level is difficult, we used tribe level: Alcelaphini, Antilopini, Bovini, Caprini, Hippotragini and Reduncini. For other groups, we used the lowest level of identification possible (genus or species). All taxonomic assignments follow the updated faunal list provided in Bibi et al. (this volume). A total of 298 specimens were molded and screened to assess their suitability for microwear and mesowear analyses. After excluding teeth where both buccal cusps were broken or damaged, 171 specimens were suitable for mesowear analysis. After an examination of the epoxy casts under the stereomicroscope, specimens with taphonomic alterations which damaged the original microwear pattern were discarded, leaving a total of 248 specimens suitable for microwear analysis.

\subsection{Sampling and analytical methods}

\subsubsection{Stable isotopes in vegetation and teeth}

Stable carbon and oxygen isotope ratios of tooth enamel are determined by an animal's diet and body water, respectively, and therefore can be used to reconstruct herbivore diets, vegetation, and local hydroclimate (Kingston and Harrison, 2007; Levin et al., 2006; e.g., Uno et al., 2011; 
Van der Merwe, 2013). Tooth enamel carbon isotopes ratios of large herbivores reflect the proportion of $\mathrm{C}_{3}$ to $\mathrm{C}_{4}$ vegetation in their diet during the time in which the tooth formed. Oxygen isotopes in enamel (or other mammalian bioapatites) are primarily controlled by the isotope ratio of precipitation but also influenced by food water; plant water; evaporative processes in soils, plants, and water sources; and animal physiology (Kohn et al., 1996; Levin et al., 2006; Luz et al., 1984). Stable carbon and oxygen isotope ratios are reported as delta $(\delta)$ values relative to the Pee Dee Belemnite (PDB) standard using permil (\%o) notation where

$$
\delta^{13} \mathrm{C}\left(\text { or } \delta^{18} \mathrm{O}\right)=\left(\mathrm{R}_{\text {sample }} / \mathrm{R}_{\text {standard }}-1\right) \times 1000
$$

and $\mathrm{R}_{\text {sample }}$ and $\mathrm{R}_{\text {standard }}$ are the ${ }^{13} \mathrm{C} /{ }^{12} \mathrm{C}\left({ }^{18} \mathrm{O} /{ }^{16} \mathrm{O}\right)$ ratios in the sample and in the standard, respectively, and the $\delta^{13} \mathrm{C}$ and $\delta^{18} \mathrm{O}$ values of PDB are defined as $0 \%$.

Today in eastern Africa nearly all woody vegetation uses the $\mathrm{C}_{3}$ photosynthetic pathway, or Calvin cycle, and nearly all low elevation (<1500 m) grasses, some sedges (e.g., Cyperus papyrus), and select shrubs (e.g., Amaranthaceae) use the $\mathrm{C}_{4}$ pathway, or Hatch-Slack cycle (Cerling and Harris, 1999; Jones and Milburn, 1978; Livingstone and Clayton, 1980; Sage et al., 2007; Tieszen et al., 1979; Young and Young, 1983). The carbon isotope ratio of $\mathrm{C}_{3}$ plants is on average around $-28 \%$ with an observed range of about -36 to $-23 \%$. The wide range in $\delta^{13} \mathrm{C}$ values in $\mathrm{C}_{3}$ plants is controlled by environmental conditions: more negative values are found in closed canopy forests whereas xeric conditions - common in lowland eastern Africa-lead to more positive values (e.g., -26 to $-23 \%$ ). $\quad \mathrm{C}_{4}$ plants exhibit a narrower range of values, from about -14 to $-10 \%$ in eastern Africa (Cerling et al., 2003a).

To establish the end-member $\delta^{13} \mathrm{C}$ values in tooth enamel $\left(\delta^{13} \mathrm{C}_{\text {enamel }}\right)$ for $\mathrm{C}_{3}$ and $\mathrm{C}_{4}$ diets, the atmospheric $\delta^{13} \mathrm{C}$ value $\left(\delta^{13} \mathrm{C}_{\mathrm{atm}}\right)$ and the enrichment in ${ }^{13} \mathrm{C}$ between diet and tooth enamel must be determined. We use the mean value of $-6.7 \%$ for the $\delta^{13} \mathrm{C}_{\mathrm{atm}}$ based on the high resolution planktonic foraminifera record from 1.8 to $1.6 \mathrm{Ma}$ from Tipple et al. (2010). We 
chose the 1.8 to 1.6 Ma interval because it best matches the age range for Olduvai Bed II ages.

We use the $\delta^{13} \mathrm{C}_{\mathrm{atm}}$ value of $-6.7 \%$ along with biosynthetic fractionation factors for $\mathrm{C}_{3}$ and $\mathrm{C}_{4}$ plants to calculate the $\delta^{13} \mathrm{C}$ values for $\mathrm{C}_{3}$ and $\mathrm{C}_{4}$ plants from 1.8 to $1.6 \mathrm{Ma}$ (Table S1). Next, we apply the enrichment factor $\left(\sum^{*}\right.$ enamel-diet $)$ of $14.1 \pm 0.5 \%$ as determined by Cerling and Harris (1999) for large ungulates to calculate ${ }^{\mathrm{TM}}{ }^{13} \mathrm{C}_{\text {enamel }}$ endmember values of $-11.9 \%$ and + $2.8 \%$ for pure $\mathrm{C}_{3}$ and $\mathrm{C}_{4}$ diets, respectively (Table S1). Note that the application of the enrichment factor, $\varepsilon_{\text {enamel-diet }} *$, is from rearrangement of the following equation,

$$
\varepsilon^{*}=\alpha^{*}-1
$$

from Craig (1954), where alpha $\left(\left\langle^{*}\right)\right.$ is the apparent fractionation factor between diet and enamel, defined as

$$
\alpha^{*}=\left(1000+\delta^{13} \mathrm{C}_{\text {enamel }}\right) /\left(1000+\delta^{13} \mathrm{C}_{\text {diet }}\right)
$$

We include these equations here as a review of the mathematically correct way to calculate endmember $\delta^{13} \mathrm{C}_{\text {enamel }}$ values from $\delta^{13} \mathrm{C}_{\text {diet }}$ values, rather than simply adding $\varepsilon^{*}$ enamel-diet $(14.1 \%$ ) to the $\delta^{13} \mathrm{C}_{\text {diet }}$ values to determine endmember $\delta^{13} \mathrm{C}_{\text {enamel values. }}$

\subsubsection{Enamel sampling, pretreatment, and isotope analysis}

Sampling of fossil teeth for stable isotopes was done at the Olduvai field station, at University College London, and at Lamont-Doherty Earth Observatory of Columbia University (LDEO). Fossil teeth were selected from ten mammalian families, with identification primarily done by Bibi et al. (this volume), but also by F.R. and M.P. in some cases. Prior to drilling, each tooth was inspected, photographed, and a sampling location on the tooth was evaluated.

The sample protocol for bulk sampling involved sampling along broken enamel surfaces whenever possible, or in some cases a lateral tooth surface, using a Dremel handheld drill with 
carbide (Brasseler) or diamond grit impregnated (Lasco) bits at low speed ( 1000 RPM). No occlusal surfaces were drilled so as to preserve these surfaces for morphological or microwear studies. The sample surface was prepared by abrading the enamel surface with the drill bit. On lateral surfaces, this removed surface adherents and the outermost enamel (ca. $100 / \mathrm{m})$. If present, cementum was drilled away to expose enamel. After visual inspection of the prepared surface with a hand lens, a narrow groove about $1 \mathrm{~mm}$ deep and 1 to $2 \mathrm{~mm}$ wide was drilled parallel to the growth axis of the tooth. Sample groove lengths varied based on tooth geometry imposed additional constraints (enamel thickness and crown length), but ideally were 10 to 15 $\mathrm{mm}$ long to average out potential seasonal variability in diet and water. Sample masses ranged from about 3 to $15 \mathrm{mg}$.

Three equid molars were serially sampled along the growth axis of the tooth to generate intratooth isotope profiles. Cementum was cleared away using the Dremel to expose a window of the fossil enamel. The exposed area was $\sim 5 \mathrm{~mm}$ wide and ran the length of the tooth crown (50 to $60 \mathrm{~mm}$ ). Samples were drilled every $3 \mathrm{~mm}$ along the growth axis of the tooth, with sample grooves oriented normal to the growth axis. Sample grooves were $\leq 1 \mathrm{~mm}$ deep, $\sim 1 \mathrm{~mm}$ wide, and 3 to $6 \mathrm{~mm}$ long. Sample masses were about 3-5 $\mathrm{mg}$.

Enamel powders from bulk and intratooth profile samples were pretreated at LDEO prior to stable isotope analysis with a weak oxidizer followed by buffered acid. Samples were treated with $3 \% \mathrm{NaOCl}$ (bleach) for 30 minutes in $1.7 \mathrm{ml}$ centrifuge tubes that were stirred every 10 minutes on a vortex mixer. After the reaction period, samples were centrifuged and the supernatant was removed. Each sample was then rinsed three times with distilled water. The rinse procedure involved adding de-ionized (DI) water, stirring on the vortex mixer, then centrifuging the sample and removing the supernatant. Next, samples were treated with $0.1 \mathrm{M}$ Na-acetate buffered acetic acid for 30 minutes, as above. Following three distilled water rinses, 
they were loosely covered and dried overnight in a fume hood. Approximately 300 to $600\lceil\mathrm{~g}$ of powdered enamel sample was weighed out into a silver capsules, along with NBS-19 standard (20-50 $(\mathrm{g})$. Samples and standards were roasted in vacuo for 2 hours at $60^{\circ} \mathrm{C}$ to remove adsorbed water, then transferred to round bottom, glass reaction vials. A strand of silver wool was added to each vial to oxidize any $\mathrm{SO}_{2}$ produced in the reaction. Sample vials were loaded immediately into a (Thermo) Kiel IV device or transferred into an oven held at $60^{\circ} \mathrm{C}$ until analyzed.

Fossil enamel samples were reacted with phosphoric acid at $70^{\circ} \mathrm{C}$ for 10 minutes in vacuo on a Kiel IV device. Exsolved gases were cryogenically transferred to a microvolume held at $-170^{\circ} \mathrm{C}$, and then transferred to second microvolume with the first held at $-70{ }^{\circ} \mathrm{C}$ to remove water. The purified sample $\mathrm{CO}_{2}$ was inlet to a dual-inlet Delta V Plus isotope ratio mass spectrometer. Carbon and oxygen isotope ratios were corrected using international and internal standards. The standard deviation of NBS-19 throughout sample runs was $\sim 0.05 \%$ for $\delta^{13} \mathrm{C}$ and $<0.10 \%$ for ${ }^{\mathrm{TM}}{ }^{18} \mathrm{O}$. Oxygen isotope values were converted from $\mathrm{CO}_{2}$ (gas) to fossil enamel (mineral) values using a fractionation factor of 1.00799, which was calculated using the temperature dependent equation for fossil enamel (Eq. 4) in Passey et al. (2007).

We calculate the dietary contribution of $\mathrm{C}_{4}$ vegetation to diet using the $\mathrm{C}_{3}$ and $\mathrm{C}_{4}$ endmember enamel values of $-11.9 \pm 4 \%$ and $+2.8 \pm 2 \%$, respectively, where uncertainty is based in observed variability in $\mathrm{C}_{3}$ and $\mathrm{C}_{4}$ eastern African plants (e.g., Cerling and Harris, 1999; Cerling et al., 2003a). We apply a two-end member mixing model, where the percent of $\mathrm{C}_{4}$ vegetation in diet is determined as

$$
\% \mathrm{C}_{4}=\left(\delta^{13} \mathrm{C}_{\mathrm{C} 3}-\delta^{13} \mathrm{C}_{\text {enamel }}\right) /\left(\delta^{13} \mathrm{C}_{\mathrm{C} 3}-\delta^{13} \mathrm{C}_{\mathrm{C} 4}\right) \times 100
$$

where ${ }^{\mathrm{TM}}{ }^{13} \mathrm{C}_{\text {enamel }}$ is the measured $\delta^{13} \mathrm{C}$ value of the sample and $\delta^{13} \mathrm{C}_{\mathrm{C} 3}$ and $\delta^{13} \mathrm{C}_{\mathrm{C} 4}$ are the calculated $\mathrm{C}_{3}$ and $\mathrm{C}_{4}$ endmember values for enamel. We propagate the uncertainty in both the 


\subsubsection{Intratooth stable isotope profiles and inverse modeling}

Intratooth stable isotope profiles of ungulate tooth enamel provide a time series of the diet and body water over the period in which the tooth enamel formed (Fricke and O'Neil, 1996; Sharp et al., 1998). In extant equids, premolars and molars form over 1.5 to 2.8 years, inclusive of crown extension and enamel maturation (Hoppe et al., 2004a). The time represented in intratooth isotope profiles can therefore be used to evaluate seasonal variability in environmental precipitation, vegetation, and diet (Metcalfe et al., 2011; Nelson, 2005; Sharp et al., 1998). Amelogenesis, or the process of enamel formation, is a two stage process that starts with a secretory stage, where the enamel matrix is deposited, followed by a protracted maturation stage, where density of the original matrix increases significantly (Suga, 1979). As a result, the isotope ratio of a given volume of enamel represents a time integrated signal of the initial period of matrix deposition plus the maturation period. Tooth enamel maturation and isotope sampling methods blur and attenuate the original isotope input signal (Passey \& Cerling, 2002; Zazzo et al, 2005). Here we apply the inverse method developed by Passey et al. (2005) to estimate the original input signal for $\delta^{13} \mathrm{C}$ (diet) and $\delta^{18} \mathrm{O}$ (body water) that more closely reflect the actual diet and body water composition of the equid during the time during in which the tooth formed. The inverse model requires input parameters that related to tooth formation, isotope sampling geometry, and isotope analysis. Input parameters relevant to tooth enamel formation, or amelogenesis, include initial enamel density $\left(\mathrm{f}_{\mathrm{i}}\right)$, enamel appositional length $\left(\mathrm{l}_{\mathrm{a}}\right)$ and maturation length $\left(\mathrm{l}_{\mathrm{m}}\right)$ (Passey and Cerling, 2002). We use parameters measured on Equus ferus przewalskii by (Blumenthal et al., 2014) as estimates for Equus oldowayensis molars used here, where $\mathrm{f}_{\mathrm{i}}=$ $22 \%, 1_{\mathrm{a}}=6 \mathrm{~mm}, 1_{\mathrm{m}}=28 \mathrm{~mm}$. Sample input variables include distance between samples $(3 \pm 0.5$ $\mathrm{mm})$ and depth $(0.7 \mathrm{~mm} \pm 0.2 \mathrm{~mm})$. The final input variables are the measured carbon and oxygen isotope data and their associated uncertainties, which were smoothed with a 3-point 
weighted mean (0.25:0.5:0.25). A measured error term, $\mathrm{E}_{\text {meas }}$, is computed from measurement uncertainties in isotope values and sample measurements. This term ultimately governs model sensitivity it is used to determine an appropriate damping factor $\left(\sum\right)$. The model requires selection of a damping factor that minimizes the difference between $\mathrm{E}_{\text {meas }}$ and the prediction error $\left(\mathrm{E}_{\mathrm{pred}}\right)$. A detailed description of the these additional model parameters and the regularization method is given in Passey et al. (2005). Model code was downloaded and adapted from Passey et al. (2005). The inverse model assumes constant growth rate. However, it is widely accepted that ungulate cheek teeth have non-linear growth rates, particularly towards the end of crown extension (Bendrey et al., 2015; Zazzo et al., 2012).

\subsubsection{Tooth wear methods \\ 2.2.2.1. Mesowear Analysis}

Mesowear analysis is a method of analyzing the gross dental wear of ungulate molars by evaluating the relief and sharpness of cusp apices which is related to the amounts of attritive and abrasive dental wear (Fortelius and Solounias, 2000). Mesowear is analyzed macroscopically from the buccal side of upper molars, preferably the paracone of M2. Unworn (and marginally worn) teeth, extremely worn teeth, and those with broken or damaged cusp apices, are omitted from mesowear analysis (Rivals et al., 2007). Mesowear was applied to Rhinocerotidae, Equidae, Giraffidae and Bovidae because of their suitable tooth morphology when using the Fortelius and Solounias (2000) method. In this study, the standardized method introduced by Mihlbachler et al. (2011) is employed. The method is based on seven cusp categories, ranging in shape from high and sharp (stage 0 ) to completely blunt with no relief (stage 6). The average value of the 
molars or on the mesio-lingual cusp of lower molars. The results are compared to the database of extant primates from Godfrey et al. (2004).

\section{Results}

\subsection{Stable Isotopes}

\subsubsection{Comparison of NISP and isotope data sets}

The relative abundance for all tooth specimens from the OGAP and Leakey Bed II fossil assemblage and for the isotope data are given in Table S2. There is close agreement between the relative abundances between the two datasets, with the coefficient of determination for interval IIA and IIB samples is significant $\left(\mathrm{R}^{2}=0.84\right.$ and 0.81 , respectively; Figure $\left.\mathrm{S} 1\right)$. In most cases, the difference in relative abundance between the NISP and isotope data sets is less than 5\%. For more abundant taxa such as Alcelaphini, Equidae, and Hippopotamidae, the difference reaches up to $20 \%$ (Table S2). The isotope dataset represents the overall fossil assemblage in Bed II and that interpretations of the isotope samples at the community level broadly apply to the fossil community.

\subsubsection{Bulk samples}

Tooth enamel $\delta^{13} \mathrm{C}$ values $(\mathrm{n}=141)$ from Bed II at Olduvai span a range of nearly $17 \%$, from -12.8 to $+4.1 \%$, with a median value of $+0.7 \%$. There is a range of $9.4 \%$ in oxygen isotope data, from -4.3 to $+5.1 \%$, with a median value of $-0.1 \%$. All carbon and oxygen isotope data are presented in Table S3, which also includes taxonomic data from Bibi et al. (this volume) and site information. More than $95 \%$ of the samples (135 of 141) come from either interval IIA (n $=63)$ or interval IIB $(n=72)$. Six additional samples come from Upper Bed II sites EF-HR and FLK (Figure 1), positioned above Tuff IIC. However, because of the small sample size we do not discuss samples from interval IIC in detail. Summary statistics from the three main Bed II 
intervals (IIA, IIB, and IIC) are presented in Table 2 and a cross plot of $\delta^{13} \mathrm{C}$ and $\delta^{18} \mathrm{O}$ for the two main intervals are show in Figure 2. We also include isotope data from 72 extant large mammals in Tanzania from Van der Merwe (2013), primarily from the Serengeti and Maswa ecosystems that lie to the west of Olduvai Gorge, to compare extant fauna to the Bed II intervals, denoted here as IIA and IIB. Histograms of carbon and oxygen isotopes from the modern and Bed II sample populations are shown in Figure 3.

Table 2 about here

The majority of the mammals from the main Bed II intervals have $\mathrm{C}_{4}$-dominated diets. In the IIA interval, the ratio of the percentages of taxa with $\mathrm{C}_{4}$-dominated: mixed: $\mathrm{C}_{3}$-dominated diets is $71: 21: 8$. In the interval IIB the ratio is $83: 15: 2$, when corrected for the overrepresentation of Hippopotamidae in interval IIB ( $\mathrm{N}=59$; discussed below in section 3.1.1.1). The modern large mammal community is also primarily comprised of mammals with $\mathrm{C}_{4}$-dominated diets (57:24:19) but about 15 to $25 \%$ less than are present in the Bed II communities, with considerable increases in the percentages of mammals with mixed and $\mathrm{C}_{3}$ dominated diets.

Figure 2 about here

Figure 3 about here

We apply the Mann-Whitney U-test (also called the Wilcoxon test) to compare carbon and oxygen isotope distributions between time intervals (IIA, IIB, and modern) because there is 
no reason to assume the data are normally distributed. Mann-Whitney U-test results indicate no significant differences between carbon isotope distributions from the three intervals (Table 3). Median $\delta^{13} \mathrm{C}$ values are nearly identical between intervals IIA, IIB, and the modern. There are however, significant differences $(p<0.05)$ in the oxygen isotope distributions between fossils and modern distributions (Table 3). The median $\delta^{18} \mathrm{O}$ values in interval IIA and interval IIB are identical $(+0.2 \%)$ when corrected for the overrepresentation of IIB Hippopotamidae. Despite their identical median values, interval IIA has a higher maximum $\delta^{18} \mathrm{O}$ value $(+5.1$ vs. $+3.7 \%$ ) which may be indicative of more evaporated water and likely, arid conditions during interval IIB times. The modern median $\delta^{18} \mathrm{O}$ value is $1.8 \%$ more positive than in intervals IIA and IIB.

\section{Table 3 about here}

The Bed II and modern carbon and oxygen data are shown as box plots for lineages (family, genus or species) for which there are three or more teeth analyzed for at least on interval (Figure 4). Elephantidae and Deinotheriidae are excluded from the box plots due to their small sample size $(\mathrm{N} \leq 2)$ and lack of continuity across intervals. Although not all groups have robust sample numbers (e.g., $\geq 5$ ), Hippotragini, Reduncini, Tragelaphini, Equidae, Hippopotamidae, Hyaenidae and Theropithecus all show increases in $\delta^{13} \mathrm{C}$ values between intervals IIA and IIB. There are no consistent $\delta^{18} \mathrm{O}$ changes across the different lineages between intervals.

Figure 4 about here

Finally, we present results of the bulk sampled isotope data by site since the scope of many archeological studies are focused at that level (Figure S2). Fossil teeth sampled in this 
study come primarily from sites HWK EE ( $\mathrm{n}=61 ; 59$ from interval IIA, 2 from interval IIB), FC (East and West; $\mathrm{n}=52$; all from IIB), and MNK ( $\mathrm{n}=20 ; 3$ from IIA, 17 from IIB). FC East and FC West are considered together due to their close proximity and same stratigraphic position. Six teeth from interval IIC come from sites FLK (Trench 69) and EF-HR; data for these sites are not presented here but are listed in Table S3. Carbon and oxygen isotopes from each site are plotted in Figure S2 for HWK EE, MNK, FC East and West, FLK, and EF-HR. All but two HWK EE samples come from interval IIA. In all sites, $\mathrm{C}_{4}$-dominated diets are prevalent. At HWK EE, the ratio of the percentages of taxa with $\mathrm{C}_{4}$-dominated: mixed: $\mathrm{C}_{3}$-dominated diets is 71:21:8 (the same as the IIA values). For FC East and FC West, the ratio is 81:17:2 and at MNK it is 90:10:0. Thus, a higher proportion of mammals sampled from FC East/FC West and MNK have $\mathrm{C}_{4}$-dominated diets and there may have been greater proportions of $\mathrm{C}_{4}$ vegetation on the landscape relative to HWK EE. Nevertheless, median $\delta^{13} \mathrm{C}$ values are nearly identical from the three sites and median $\delta^{18} \mathrm{O}$ values are only slightly $(<1 \%)$ more negative at FC East and West and at MNK than at HWK EE (Table S4). U-test results show no statistically significant differences $(p>0.05)$ between the $\delta^{13} \mathrm{C}$ and $\delta^{18} \mathrm{O}$ distributions at the three sites (Table S5).

\subsubsection{Artiodactyls}

Bovidae are common in the assemblage, comprising $43 \%$ of all Bed II samples in the OGAP and Leakey collections (Bibi et al., this volume), and box plots of their carbon and oxygen data are presented by tribe in Figure 5. There are shifts towards more positive $\delta^{13} \mathrm{C}$ distributions (median and/or ranges) between intervals IIA and IIB for Tragelaphini, Reduncini, and Hippotragini. Alcelaphini $\delta^{13} \mathrm{C}$ distributions remain unchanged, but their $\delta^{18} \mathrm{O}$ median values increase by $\sim 1 \%$ between intervals IIA and IIB. We applied the same U-test used to compare distributions in intervals IIA and IIB to the Alcelaphini isotope values, one of only two lineages with $\geq 5$ specimens analyzed per interval (Table 3). Only $\delta^{18} \mathrm{O}$ values show a significant change between 
intervals IIA and IIB. In other bovid tribes, the $\delta^{18} \mathrm{O}$ trends from interval IIA to IIB are mixed, probably in part due to small sample sizes. For example, Tragelaphini $\delta^{18} \mathrm{O}$ values increase in range and become more positive in interval IIB, while Hippotragini values become more negative between IIA and IIB (Figure 5). Among Antilopini, which are only sampled from interval IIA, the smaller form, cf. Antidorcas recki has a $\mathrm{C}_{4}$-dominated diet, whereas the larger form (possibly Aepyceros) shows a mixed diet.

Figure 5 about here

Bibi et al. (this volume) identified at least 3 species based on tooth size: Megalotragus isaaci, Alcelaphini small sp., and Alcelaphini sp. indet. Using the relatively large sample of Alcelaphini from Bed II (N=33), we compare $\delta^{13} \mathrm{C}$ or $\delta^{18} \mathrm{O}$ values among the three types of Alceliphini to explore whether there is isotopic evidence for niche partitioning. The data show no such evidence (Figure S3).

Other Bed II artiodactyls have $\mathrm{C}_{4}$-dominated or mixed diets, with the exception of two Giraffa stillei, one from HWK EE (interval IIA) and one from EF-HR (interval above IIC). A combined five Sivatherium $\delta^{13} \mathrm{C}$ values from the two main intervals indicate $\mathrm{C}_{4}$-dominated or mixed diets; their $\delta^{18} \mathrm{O}$ values are similar between the two intervals.

Eighteen Hippopotamus gorgops teeth were sampled, two from interval IIA and sixteen from IIB. Interval IIA $H$. gorgops have $\delta^{13} \mathrm{C}$ values of -1.9 and $-2.4 \%$ and $\delta^{18} \mathrm{O}$ values of -3.8 and $-3.6 \%$, the latter of which are the most negative values from all IIA fauna analyzed. In interval IIB, the median $\delta^{13} \mathrm{C}$ value for the sixteen $H$. gorgops is $-0.1 \%$ (min: $-2.8 \%$; max: $+1.1 \%$ ); the median $\delta^{18} \mathrm{O}$ value is $-2.6 \%$ (min: $-4.3 \%$; max: $-1.0 \%$ ). Hippopotamidae 
enamel typically yields the lowest $\delta^{18} \mathrm{O}$ values within a given ecosystem (Bocherens et al., 1996; Cerling et al., 2008).

Two Suidae genera, Kolpochoerus and Metridiochoerus both have $\mathrm{C}_{4}$-dominate diets (77 to $91 \% \mathrm{C}_{4}$ ), with a median $\delta^{13} \mathrm{C}$ value of $-0.1 \%$ (min: $-0.6 \%$; max: $+1.5 \%$ ). Kolpochoerus $\delta^{18} \mathrm{O}$ values are about 1 to $2 \%$ more depleted than coeval Metridiochoerus values, suggesting different diets, water sources, or physiologies.

\subsubsection{Perissodactyls}

Perissodactyls from Bed II include relatively rare Rhinocerotidae and abundant Equidae, the latter of which are second only to Alcelaphini in the number of specimens analyzed and overall abundance in Bed II. In interval IIA, all five Rhinocerotidae samples analyzed indicate $\mathrm{C}_{4}$-dominated diets. Three are identified as Ceratotherium cf. simum while the others are identified only to family (Figure 4; Table S6). In interval IIB, there is one rhino (Ceratotherium) with a $\mathrm{C}_{4}$-dominated diet and one (Rhino indet. ?Diceros) with a $\mathrm{C}_{3}$-dominated diet, presumably similar to the extant grazing and browsing rhinos. The median $\delta^{18} \mathrm{O}$ value of the interval IIA samples is $\sim 1 \%$ more enriched than the interval IIB value.

Equidae teeth analyzed for isotopes are assigned mostly to Equus oldowayensis $(\mathrm{n}=18)$ with smaller number coming from Eurygnathohippus cornelianus $(\mathrm{n}=5)$ and one specimen listed as Equidae gen. et $s p$. indet. Equid $\delta^{13} \mathrm{C}$ values indicate $\mathrm{C}_{4}$-dominated diets for 21 of 24 analyzed specimens (Table S3 and Figure 4). Interval IIB equids have a more positive median $\delta^{13} \mathrm{C}$ values and smaller interquartile range than in IIA which suggests decreased dietary breadth during interval IIB times. The $\delta^{18} \mathrm{O}$ values are slightly more negative in IIB (Figure 4). Despite these differences, U-test results comparing interval IIA and IIB Equidae show no significant differences in either carbon $(p=0.1754)$ or oxygen $(p=0.3312)$ isotope distributions (Table 3$)$. 
We compare the $\delta^{13} \mathrm{C}$ or $\delta^{18} \mathrm{O}$ values between E. oldowayensis and Eu. cornelianus. The $\delta^{13} \mathrm{C}$ values largely overlap, although the smaller number of Eu. cornelianus suggest a diet with a higher proportion of $\mathrm{C}_{4}$ vegetation, whereas E. oldowayensis had a broader dietary range (Figure S3C). The $\delta^{18} \mathrm{O}$ values show no differences between the two equid species (Figure S3D).

\subsubsection{Proboscideans}

Proboscidean material is rare from the available dataset of Bed II, with only two deinothere and one elephantid specimen analyzed. The deinotheres from interval IIA are the most negative $\delta^{13} \mathrm{C}$ values measured from Bed II and functionally define a $\mathrm{C}_{3}$ endmember diet $\left(-12.7 \%\right.$ ). The $\delta^{18} \mathrm{O}$ values of -1.3 and $-1.8 \%$ are also relatively negative compared to most other values from interval IIA (Figure 3). $\mathrm{A} \delta^{13} \mathrm{C}$ value of $+1.8 \%$ from a single Elephas recki specimen from IIB puts it on the opposite end of the dietary spectrum $\left(93 \% \mathrm{C}_{4}\right)$ from the Deinotheriidae.

\subsubsection{Primates}

Primates are also rare in Bed II. Four Theropithecus oswaldi teeth, one from interval IIA and three from IIB, have a median $\delta^{13} \mathrm{C}$ value of $0.0 \%$, indicating $\mathrm{C}_{4}$ dominated diets (73 to 94 $\left.\% \mathrm{C}_{4}\right)$. The $T$. oswaldi from interval IIA has more negative median $\delta^{13} \mathrm{C}$ and $\delta^{18} \mathrm{O}$ values than those from interval IIB (Figure 4).

\subsubsection{Carnivores}

Four hyaenid teeth (Crocuta sp.) were analyzed from Bed II, one from interval IIA and three from IIB. The IIA specimen has a $\delta^{13} \mathrm{C}$ value of $-4.3 \%$ and the three from interval IIB have values ranging from -3.4 to $-0.3 \%$ (Figure 4 ). Carnivore bioapatite is depleted $\sim 1.3 \%$ with respect to their diet (Fox-Dobbs et al., 2006), so the Crocuta sp. prey at Olduvai were

herbivores with mixed and $\mathrm{C}_{4}$ dominated diets. Crocuta $\delta^{18} \mathrm{O}$ values range from -2.9 to $+0.5 \%$. 
The Bed II Crocuta stable isotope values are similar to those of modern hyenas from Tanzania reported by van der Merwe (2013) and plotted in Figure 4.

\subsubsection{Serially sampled equids}

The measured and modeled isotope data from the three Equus oldowayensis intratooth profiles are given in Table $\mathrm{S} 6$ and additional model input and output data $\left(\mathrm{E}_{\text {meas }}, \mathrm{E}_{\text {pred, }}\right.$ and $\left.\varepsilon\right)$ are provided in Table S7. The intratooth profiles are plotted in Figure 6. The modeled $\delta^{13} \mathrm{C}$ and $\delta^{18} \mathrm{O}$ values in the profiles range from -2.3 to $+2.1 \%$ and -2.1 to $+1.6 \%$, respectively, which reflect the estimated range of dietary input and body water variability, after being corrected for blurring due to enamel maturation and sampling (Table S6). The tooth from the Lemuta interval at HWK EE (IIA interval, specimen L10-523) shows greater seasonal variability in both isotope ratios than the other two profiles, L1-48 (MNK Main) and L62-104 (FC West), that come from interval IIB (Figure 6). For example, the estimated diet of the E. oldowayensis from IIA ranges from 66 to $97 \% \mathrm{C}_{4}$, whereas the diets of the other two range from 74 to $87 \% \mathrm{C}_{4}$ (specimen $\mathrm{L} 1-48$ ) and from 91 to $97 \% \mathrm{C}_{4}$ (specimen L62-104). All three profiles indicate mostly $\mathrm{C}_{4}$-dominated diets with the exception of some of the samples from tooth L10-523 and one sample from tooth L1-48 indicating seasonally mixed $\mathrm{C}_{3}-\mathrm{C}_{4}$ diets (Table S6).

Figure 6 about here

\subsection{Tooth wear}

All the results from the mesowear and microwear analyses are provided in Table 4 for each site and taxa. Raw data are available in the online supplementary material Table S8. Even if all teeth available in the collections had been sampled, the sample size for many taxa would still 
be very low. The results from taxa with small sample size $(\mathrm{N}<3)$ are reported but will not be used in the interpretations (see section 4. Discussion).

Small samples excluded, mesowear scores range from MWS $=1.8$ in Reduncini to MWS $=5.2$ in Equidae (Table 4). This range of values corresponds to those for extant grass-dominated mixed feeders and grazers (Fortelius and Solounias 2000, Mihlbachler et al. 2011). In comparison to extant reference samples, the microwear patterns observed correspond to the range of extant mixed feeders and grazers (Figure 8; Table 4). The detailed results are reported for each taxon, comparing the assemblages from intervals IIA and IIB.

\section{Table 4 about here}

\subsubsection{Artiodactyls}

Bovidae are represented by six tribes (Table 4). In general, bovids plot among the extant mixed feeders (Figure 8A). Sample size is significant for Alcelaphini, Antilopini, and Reduncini.

Alcelaphini provided the largest sample, both at IIA ( $\mathrm{N}=45$ for mesowear, $\mathrm{N}=35$ for microwear) and IIB ( $\mathrm{N}=38$ for mesowear, $\mathrm{N}=40$ for microwear). The two samples show mesowear scores similar to extant grass-dominated mixed feeders and grazers. The sample from IIB has higher values than in IIA, but the values overlap slightly (Figure 7). The microwear pattern with intermediate numbers of scratches is characteristic of mixed feeders (Figure 8A). In terms of numbers of pits and scratches, microwear pattern is very similar in the two stratigraphic units (Table 4). However, some differences are reported with a higher percentage in interval IIA of large pits and hypercoarse scratches, as well as wider scratches (higher SWS).

The Hippotragini, even with relatively small sample sizes, show mesowear and microwear values which are very similar to those previously reported for the Alcelaphini (Figures 7 and 8A). The two samples from intervals IIA and IIB plot among the mixed feeders. 
Nevertheless, the sample from interval IIA displays higher percentage of large pits, wider scratches and presence of hypercoarse scratches than in interval IIB.

The Antilopini only provided data in the interval IIA $(\mathrm{N}=13)$. The mesowear score plots among the mixed feeders, at the limit of the values for extant browsers and grazers (Figure 7). The same result is obtained from microwear (Figure 8A). As the Alcelaphini and the Hippotragini from interval IIA, the Antilopini show high percentages of large pits (Table 4), but here associated with gouges which indicate the presence of large-sized particles of grit on the vegetation consumed.

Reduncini show low mesowear scores corresponding to browsing or browse-dominated mixed feeding (Figure 7), but high numbers of scratches indicating grazing (Figure 8A). There is a clear discrepancy between the two proxies, especially for the sample from interval IIA (the sample size from interval IIB is very small).

Bovini and Tragelaphini are only represented by very small samples. For the two tribes, the specimens from interval IIA show a low mesowear value and low numbers of scratches consistent with browsing (Figures 7 and 8A). For the specimens from interval IIB, data from a single proxy are available, i.e. microwear for the Bovini and mesowear for the Tragelaphini. For the Bovini, microwear shows intermediate values consistent with mixed feeding (Figure 8A). For the Tragelaphini, the single mesowear value suggests mixed feeding (Figure 7). However, the low sample size does not allow definite interpretation.

Caprini are only represented by a single specimen of uncertain stratigraphic provenience (surface find). The low number of scratches would suggest a browsing trend, but sample size is too small to allow an interpretation (Figure 8A).

The giraffid Sivatherium maurusium shows intermediate mesowear and microwear values. The mesowear values show a tendency toward grazing (MWS $>2$ ), while the microwear 
pattern, with low number of scratches (NS < 17), suggests more browsing at the time of death (Figure 8B). As previously reported for most of the bovids, the sample from interval IIA shows higher percentages of large pits, gouges, hypercoarse scratches, but also cross scratches, than in interval IIB (Table 4). Consequently, due to the presence of hypercoarse scratches, the scratches are generally also wider in interval IIA. These higher values in interval IIA would suggest the presence of high quantities of grit ingested together with the vegetation.

For the hippopotamid Hippopotamus gorgops, tooth mesowear indicates grazing (in interval IIB), while microwear suggests mixed feeding (both in intervals IIA and IIB). The microwear pattern is also characterized by a high frequency of cross scratches in intervals IIA and IIB, and the presence of coarse and hypercoarse scratches (high SWS) in interval IIB (Table 4).

The suids Kolpochoerus sp. and Metridiochoerus sp. were analyzed only through microwear. The four samples plot in the grazing confidence ellipse or in the grass-dominated mixed feeders (Figure 8B). All samples have high percentages of cross scratches (from 90 to $100 \%$ ) and many samples display large pits, gouges, puncture pits and hypercoarse scratches. The combination of all these features would suggest these species consumed leaves, grasses, wood bark, and importantly, might have relied on a rooting diet (Medin et al. 2015).

\subsubsection{Perissodactyls}

The equids Equus oldowayensis and Eurygnathohippus cornelianus have high mesowear values (MWS $=4$ to 5.2) which correspond to extant grazers (Figure 7). Mesowear values for the two species in interval IIB are higher than those in interval IIA suggesting more abrasive diets in the samples from interval IIB. Regarding the microwear pattern, Equus oldowayensis shows less scratches than Eurygnathohippus cornelianus, indicating that Eurygnathohippus cornelianus was 
more of a grazer than Equus oldowayensis (Figure 8B). In each assemblage, Equus oldowayensis also has more large pits and gouges than Eurygnathohippus cornelianus. It is also significant that the samples from interval IIB show a higher number of scratches than those from interval IIA, indicating more abrasion in interval IIB, as previously reported with mesowear.

For the Rhinocerotidae, Ceratotherium cf. simum, the sample from interval IIA ( $\mathrm{N}=3$ ) displays a high number of scratches with values tending towards the extant grazers (Figure 8B). The absence of large pits and gouges and the presence of mostly fine scratches (low SWS value) also confirm grass-dominated diets (Table 4).

\subsubsection{Proboscideans}

The elephantid Elephas recki is represented by a single specimen showing a microwear pattern with intermediate number of scratches plotting in between the extant browsers and grazers (Table 4 and Figure 8B).

\subsubsection{Primates}

Primates are represented by three specimens attributed to Theropithecus oswaldi. In comparison to extant primates with known diets (Godfrey et al. 2004), the specimens from intervals IIA and IIB plot among the species which feed on grass such as Theropithecus gelada, Hapalemur griseus and H. simus (Figure 9).

Mesowear scores are generally higher in the samples from interval IIB compared with those from interval IIA, with the exception of the small sample of Reduncini (Figure 7). This would indicate a more abrasive diet for the populations of herbivores from interval IIB. 
In terms of tooth microwear, the samples from interval IIA and IIB have the same ranges of scratches, but the samples from interval IIA tend to have higher numbers of pits than those from interval IIB. The samples from interval IIA usually have more large pits and gouges, and wider scratches (higher SWS and presence of hypercoarse scratches) than those from interval IIB (Table 4). All these features would suggest the ingestion of exogenous particles (dust, grit) related to drier conditions in interval IIA.

\section{Discussion}

\subsection{Dietary reconstructions}

We find no major shifts in overall dietary ecology across the Oldowan-Acheulean transition, although there are changes at the tribe or family level. The stable isotope data suggest a decrease in the number of mammals with mixed and $\mathrm{C}_{3}$-dominated diets in interval IIB. However, limited sample size for the isotope data set and hominin preference for mammals with $\mathrm{C}_{4}$-dominated diets (e.g., Alcelaphini) may bias the record against browsers (Patterson et al., 2017). Mesowear scores generally increase between intervals IIA and IIB, suggesting an increase in grazing. Microwear data indicates more abrasive diets in interval IIA based on the higher occurrence of scratches. The combination of tooth wear and stable isotope analyses provides two independent methods for reconstructing mammalian diets. A combined approach has the potential to yield more refined paleodietary and paleovegetation reconstructions. Throughout the ensuing discussion of dietary reconstructions based on tooth wear and stable isotopes, it is important to keep in mind that each method records diet over different periods of an animal's life. Microwear analysis represents diet over the previous days or weeks before death; mesowear over months to years; and stable carbon isotopes record diet during tooth formation, which ranges from $\sim 1-2$ years in ungulates and up to a decade or more in proboscideans (Hoppe et al., 2004b; Uno et al., 

term (i.e., seasonal) differences in diet. Dietary discrepancies are expected to be more frequently observed among mixed feeders or dietary generalists than in dedicated grazers or browsers.

Tooth enamel carbon isotope values indicating $\mathrm{C}_{4}$-dominated diets in eastern Africa are usually assumed to signify grazing taxa, whereas values indicative of $\mathrm{C}_{3}$-dominated diets are usually assumed to represent browsing taxa. This assumption is probably valid for taxa younger than $\sim 10 \mathrm{Ma}$, when carbon isotopes of plant wax biomarkers first show evidence of $\mathrm{C}_{4}$ vegetation in eastern Africa (Uno et al., 2016). It is further supported by the earliest record of $\mathrm{C}_{4}$-dominated diets in eastern African from equids at 9.9 Ma (Uno et al., 2011). It is possible that there were mixed $\mathrm{C}_{3}-\mathrm{C}_{4}$ grasslands in eastern Africa in the past, but this would require taxa with $\mathrm{C}_{4}$ dominated diets like equids, which today are $\mathrm{C}_{4}$ grazers, to have been selective grazers based on photosynthetic pathway (or some associated characteristics). It is also possible that $\mathrm{C}_{4}$-dominated diets, present across the orders Artiodactyla, Perissodactyla, and Proboscidea by $\sim 7 \mathrm{Ma}$ in Africa, were derived from combination of $\mathrm{C}_{4}$ grasses and shrubs (e.g., Amaranthaceae). Much of this speculation can be addressed through a combined tooth wear and isotope approach to test whether a $\mathrm{C}_{3}$ or $\mathrm{C}_{4}$ dietary signal, determined from the isotope data, is associated with a grazing or browsing diet based on microwear patterns or mesowear scores. This approach was at Laetoli, where isotopes and mesowear show $\mathrm{C}_{3}$-dominated and mixed diets were comprised mostly of $\mathrm{C}_{3}$ browse (Kaiser, 2011; Kingston, 2011), although some of the large mammals were also exploiting $\mathrm{C}_{3}$ grasses, which were identified through phytolith analysis (Rossouw and Scott, 2011).

The combined tooth wear and stable isotope data indicate $\mathrm{C}_{4}$ grass-dominated diets for most taxa from Bed II at Olduvai (Figures 2 to 5). Evaluating the two methods independently in each interval, we find that the tooth wear data show taxa from interval IIA were grass-dominated 


\subsubsection{Artiodactyls}

A more detailed look at different taxonomic groups further illustrates the utility of combined tooth wear and isotope data. Among species with a large sample size for tooth wear analyses, Alcelaphini show grass-dominated mixed feeding and grazing traits (Figure 8A). This is in close but not exact agreement with the carbon isotope data, which indicate $\mathrm{C}_{4}$-dominated diets (Figures 3 and 5). The grass-dominated mixed feeding signal in Alcelaphini comes from a low number of scratches $(<20)$ in the microwear data (Table 4$)$ that results in placement outside of the $95 \%$ confidence centroid for grazers. Their mesowear scores fall within the modern range of grazers and the upper half of the mixed feeding range (Figure 7). The Hippotragini data are 

the lower range of extant grazers and microwear data fall outside of the $95 \%$ confidence centroid for grazers. In both Alcelaphini and Hippotragini, the lack of scratches could possibly be a result of browsing on $\mathrm{C}_{4}$ shrubs, which would reconcile the microwear and carbon isotope data. Bonnefille (1984) identified pollen from a $\mathrm{C}_{4}$ shrub from the family Amaranthaceae, Aerva javanica (listed as A. persia in that publication) in a single sample in Lower Bed II at VEK. This does not constitute evidence for widespread $\mathrm{C}_{4}$ shrubs, but it does document the presence of at least one such taxon during Bed II times.

Both tooth wear and the isotope data for the Antilopini cf. Antidorcas recki point to predominantly mixed feeding (Figures 5,7 and 8). The other bovid tribes have sample sizes that are too small $(\mathrm{N} \leq 4)$ to apply these methods, so interpretations are lower confidence. Tooth wear from Tragelaphini point towards browsing, whereas isotope data from a relatively small sample $(\mathrm{N}=6)$ suggest a wide dietary breadth ranging from $\mathrm{C}_{3}$ - to $\mathrm{C}_{4}$-dominated diets.

Reduncini are deemed $\mathrm{C}_{4}$ grazers based on the agreement between carbon isotopes and microwear, but have somewhat low mesowear scores (mean of 0.5 to 1.80 in IIA and IIB, respectively). Extant Reduncini are grazers (Cerling et al., 2003b), but the mesowear characteristics of Redunca redunca and Kob ellipsiprymnus show high relief and rounded cusps, two features associated with browsing or mixed feeding (Fortelius and Solounias, 2000). Their preference for soft grasses often found in wetlands is one possible explanation for the discrepancy between the isotope and mesowear signature. Two Bovini, one from each interval, are classified as mixed feeders based on their microwear and a single mesowear value, whereas the isotope value from a single sample in IIA yields a $\mathrm{C}_{4}$-dominated diet $\left(84 \% \mathrm{C}_{4}\right)$.

Carbon isotope data from a small number of cf. Sivatherium or Sivatherium maurusium $(\mathrm{N}=5)$ place their diets on the boundary of $\mathrm{C}_{4}$-dominated and mixed diets, which is supported 
by the mean mesowear scores that suggest mixed to grazing diets in both intervals (Figure 7). However, the microwear data indicate browse-dominated mixed diets. A seasonal dietary shift from grazing to browsing could be invoked to reconcile the isotope and microwear data.

Sixteen of eighteen Hippopotamidae analyzed for isotopes come from interval IIB, and their diets range from mixed to $\mathrm{C}_{4}$-dominated. Interval IIA hippos have $\mathrm{C}_{4}$ grass-dominated mixed diets based on isotope and microwear data. In interval IIB, carbon isotope values from MNK are more positive than those from FC East and West (Figure S2), possibly illustrating habitat variability over very short distances (Figure 1), but collectively indicating mixed and $\mathrm{C}_{4^{-}}$ dominated diets. Mesowear scores in interval IIB indicate a grazing diet. Microwear data from IIA indicate a grass-dominated mixed diet whereas in interval IIB it suggests mixed diets (with more browse relative to IIA specimens).

Two Suidae genera from Bed II, Metridiochoerus and Kolpochoerus, both have $\mathrm{C}_{4}$ dominated diets (Figure 5). Bibi et al. (this volume) have identified multiple species for each genus. We analyzed three samples from the Kolpochoerus limnetes and K. paiceae lineage (the latter being synonymous with $K$. oldowayensis) plus one specimen designated Kolpochoerus cf. limnetes, and three from a different lineage, $K$. majus, which is thought to be descended from $K$. phillipi (Souron et al., 2015). The K. limnetes/paiceae lineage has morphological features such as increased hypsodonty and length in the third molars and reduced premolars that are interpreted as grazing adaptations, whereas the bunolophodont lineage, $K$. phillipi/majus, has a less specialized dentition and thus possibly had a more diverse and omnivorous diet (Souron et al., 2015).

From our limited sample size, there does not appear to be any difference in $\delta^{13} \mathrm{C}$ between the two Kolpochoerus lineages. Three of the K. limnetes/paiceae from FC East and FC West have nearly identical $\delta^{13} \mathrm{C}$ values ( $-0.5,-0.5$ and $-0.6 \%$ ), suggesting a narrow dietary niche. 
K. phillipi/majus from HWK EE and FC West all have similar $\delta^{13} \mathrm{C}$ values with slightly more variability than in the K. limnetes/paiceae subset of samples (Table S3). Microwear data support the dietary differences posited by Souron et al. (2015), where higher number of scratches in K. limnetes/paiceae (avg.: 23.9; range 20.5 to 28; N=9) suggests a diet focused on grasses, whereas $K$. majus has a lower number of scratches (avg.: 19; range 13.5 to $23.5 ; \mathrm{N}=6$ ) and a higher range, indicating more variable diet (more intra-specific variability) that would fit with a more generalist diet. For Metridiochoerus, there is not enough data from the different species to evaluate dietary differences. More broadly for the Suidae, the diets of the two genera cannot be differentiated based on carbon isotopes (Figure 5).

In contrast to carbon isotopes, oxygen isotopes and microwear data indicate niche partitioning between the two genera within their $\mathrm{C}_{4}$-dominated diet regime. Kolpochoerus, which is the more abundant of the two suid genera (Bibi et al., this volume), has more negative $\delta^{18} \mathrm{O}$ values and higher percentages of pits than Metridiochoerus. More negative $\delta^{18} \mathrm{O}$ values indicate a greater water dependence for Kolpochoerus. This pattern is also present in Turkana Basin Suidae (Harris and Cerling, 2002). There is little to no temporal change in Suidae diet between intervals IIA and IIB. There are no values from modern Suidae from Tanzania to compare the Bed II data to.

\subsubsection{Perissodactyls}

Olduvai Equidae were primarily $\mathrm{C}_{4}$ grazers based on tooth wear and carbon isotope results, all of which comes from large sample sizes (Tables 4 and S3). Mean Equidae mesowear scores range between 4.0 to 5.2, values associated with extant grazers (Figure 7 and Table 4). Microwear results suggest grass-dominated mixed feeding to grazing (Figure 8B). Carbon isotope from bulk and serial sampling indicate primarily $\mathrm{C}_{4}$-dominated diets (median $=90 \% \mathrm{C}_{4}$, 
range: 47 to $100 \%$ ) with seasonal mixed diets (Figures 3, 4 and 6). The minor amounts of $\mathrm{C}_{3}$ vegetation in their diets may have included some $\mathrm{C}_{3}$ grasses, although the microwear data suggests minor browsing (Figure 8B). Modern equids (zebra) from Tanzania have similar $\delta^{13} \mathrm{C}$ values to Bed II Equidae, whereas modern $\delta^{18} \mathrm{O}$ values are about $3 \%$ more positive than Bed II values (Figure 4).

We find clear evidence for niche-partitioning between the two Equidae from Bed II. $E$. oldowayensis, the most abundant taxon in the Bed II fossil record, had a mixed to $\mathrm{C}_{4}$-dominated diet that likely included occasional browse, whereas Eu. cornelianus had a diet comprised almost entirely of $\mathrm{C}_{4}$-grasses. This is supported by all three proxies: The smaller species, $E u$. cornelianus, has a higher average mesowear score $(5.16 ; \mathrm{N}=6)$ than E. oldowayensis (4.51; $\mathrm{N}=53$ ). Carbon isotope ratios of Eu. cornelianus are consistently more positive and have a smaller range of values than those of E. oldowayensis (Figure S3C). Finally, microwear results show higher number of higher scratches for Eu. cornelianus $(\mathrm{NS}=19.8 ; \mathrm{N}=12)$ than for Equus (NS=17.6 N=50), indicating a higher intake of grass in the former taxon. Eu. cornelianus shows a smaller range in NS values (17.5-23) than E. oldowayensis (10.5-25), suggesting a more variable diet for the latter, although sample size is smaller for E. oldowayensis.

Bed II Rhinocerotidae have diets similar to the two extant species, one with $\mathrm{C}_{3^{-}}$and the other with a $\mathrm{C}_{4}$-dominated diet. Interval IIA specimens have a narrow range of carbon values indicative of $\mathrm{C}_{4}$ diets and IIB is represented with one $\mathrm{C}_{3}$ feeder and one $\mathrm{C}_{4}$ feeder. Microwear data from three teeth in IIA are in excellent agreement with the isotope data.

\subsubsection{Proboscideans}

Isotope data from a single Elephas molar suggest a $\mathrm{C}_{4}$-dominated diet while microwear data indicate a mixed diet (Figures 3 and 8B). With only a single sample, it is difficult to make strong 
dietary interpretations, but the reconstructed diet is similar to that of Elephas of similar age (1.9 to $1.55 \mathrm{Ma}$ ) from the Turkana Basin, where carbon isotopes (median $=-0.2 \%$ ) indicate $\mathrm{C}_{4}$ dominated diets (Cerling et al., 2015). The fossil evidence shows Elephas was rare at Olduvai (Bibi et al, this volume; (Leakey, 1971). This is intriguing for several reasons. First, $\mathrm{C}_{4}$ vegetation and open habitats preferred by Elephas were abundant. Second, although Middle Bed II exhibits a top-heavy faunal structure (Bibi et al., this volume) relative to the modern Serengeti fauna, it seems mega herbivores (>1,000 kg) like Elephas were much rarer than the macro herbivores (100 to 1,000 kg), most of which were grazing Bovidae or Equidae. This could be the result of the larger bones of mega herbivores being differentially preserved in the Olduvai fossil assemblages due to their lower potential for burial and fossilization (Behrensmeyer and Boaz, 1980). However, it must also be considered that the majority of the assemblages analyzed here were likely accumulated, at least in part, by hominins. HWK EE and MNK T5 show evidence of hominins butchering the bones of Proboscideans, but few skeletal parts of these animals are represented at the sites, suggesting some of the fossils that are present in the collections were selectively transported from an off-site location where they were likely scavenged by hominins (see Pante et al., this volume). The carcasses of macro herbivores are more evenly represented and were likely acquired by hominins more often than those of mega herbivores based on their relative dominance in the collections.

\subsubsection{Primates}

This is the first study to our knowledge to combine microwear $(\mathrm{N}=3)$ and stable isotope $(\mathrm{N}=4=)$ data from Theropithecus oswaldi, and the first isotope and tooth wear data reported from Olduvai for this species. Carbon isotope data (median $=0.0 \%$ ) indicate a diet of $81 \% \mathrm{C}_{4}$ vegetation, equivalent to the diet of Paranthropus boisei from Bed I (van der Merwe et al., 
2008). The microwear data fall within the range of the extant Theropithecus gelada, which has grass dominated diets (Figure 9). Thus, there is strong consilience from the isotope and tooth wear approaches that support $\mathrm{C}_{4}$ grazing by $T$. oswaldi.

The median $\delta^{13} \mathrm{C}$ value of $T$. oswaldi from Olduvai is $1.0 \%$ more positive than that from coeval T. oswaldi $($ median $=-1.0 \% ; \mathrm{N}=24)$ reported from the Turkana Basin from 1.95 to 1.5 by Cerling et al. (2013). The median $\delta^{18} \mathrm{O}$ values of $T$. oswaldi from the two regions are indistinguishable; Bed II is $+1.2 \%$ and Turkana is $+1.1 \%$.

\subsection{Paleoenvironmental reconstruction}

\subsubsection{Vegetation}

We infer a preponderance of $\mathrm{C}_{4}$ grass on the landscape during the accumulation of Bed II sediments based on dietary reconstructions from isotope $(\mathrm{N}=141)$, mesowear $(\mathrm{N}=156)$, and microwear $(\mathrm{N}=228)$ analyses of fossil teeth. The data show no evidence for significant vegetation change across the Oldowan-Acheulean transition. This view of abundant $\mathrm{C}_{4}$ vegetation is consistent with carbon isotope based vegetation reconstructions from lower Bed II and Lemuta soil carbonates (Cerling and Hay, 1986; Sikes, 1994). The soil carbonate $\delta^{13} \mathrm{C}$ values range from -6.8 to $-0.6 \%$ with a median of $-4.2 \%$. We convert the soil carbonate $\delta^{13} \mathrm{C}$ values to fraction woody cover $\left(f_{\mathrm{wc}}\right)$, a more tangible representation of vegetation, following the equation developed by Cerling et al. (2011). The $f_{\mathrm{wc}}$ from lower Bed II and the Lemuta Beds range from 0.42 to 0.03 with a median value of 0.22 , where values $>0.4$ represent bushland or shrub land vegetation classifications ( $\mathrm{N}=1$ at Bed II), values from 0.4 to 0.1 represent wooded grasslands $(\mathrm{N}=14)$, and $f_{\mathrm{wc}}$ values $<0.1$ represent grasslands $(\mathrm{N}=3)$. None of the data indicate forested or closed canopy conditions $(\geq 0.8)$. The majority of the soil carbonate data fall within the wooded grassland vegetation classification. A wooded grassland, with heterogeneous 
pockets of more and less dense areas of woody cover, fits well with the overall proportion of grazing mammals recovered from Bed II deposits (Bibi et al. this volume) and from our tooth wear and isotope data.

In addition to soil carbonate data, carbon isotopes from $n$-alkanes (terrestrial plant waxes) have been used to reconstruct vegetation from slightly older (1.9 to 1.8 Ma) Bed I sediments (Magill et al., 2013a). Plant wax data show precessionally driven vegetation changes that range from forest to grassland over the $\sim 100 \mathrm{kyr}$ interval. The Bed I plant wax record suggests there were periods with more woody $\mathrm{C}_{3}$ vegetation (high $f_{\mathrm{wc}}$ ) on the landscape, especially during middle Bed I to lowermost Upper Bed I times, around 1.85 to $1.83 \mathrm{Ma}$, where $n$-alkanes values are 3 to $4 \%$ more negative than other "wet" cycles in the plant wax records. Faunal records show a temporary shift towards more humid or wooded conditions during middle Bed I times based on an increase in Reduncini and Tragelaphini, taxa associated with humid and wooded environments, respectively ((Kappelman, 1984); Figure 9B and C in Bibi et al., this volume). Both lines of evidence point to greater water availability and woody vegetation in middle Bed I compared to Bed II. Bed II faunal distributions (Bibi et al., this volume; Prassack et al., this volume), dietary reconstructions presented here and in Rivals et al. (this volume), and previously published soil carbonate data do not support the presence of widespread, dense woody cover at any period studied in Bed II.

Paleovegetation in Upper Bed I and Bed II has also been reconstructed from plant remains. Aside from an early study using pollen (Bonnefille, 1984), most work has focused on the use of phytoliths (e.g., Albert et al., 2015a; Albert et al., 2009; Barboni et al., 2010) and plant macrofossils (Bamford, 2012; Bamford et al., 2006; Bamford et al., 2008; Habermann et al., 2016b). There is good agreement between the vegetation reconstructions derived from phytoliths and the tooth wear and enamel isotope data presented from intervals IIA and IIB. 
presence in ancient sediments confirms their presence on the landscape, phytolith abundances should not be taken at face value to reflect plant abundances in the past (Albert et al., 2006).

\subsubsection{Hydroclimate}

Hydroclimate change across the Oldowan-Acheulean transition can be assessed through the bulk and the intratooth isotope profile $\delta^{18} \mathrm{O}$ values (Figures 3 and 6). The Mann-Whitney U-test indicates no significant differences in $\delta^{18} \mathrm{O}$ distributions between intervals IIA and IIB (Table 3). However, the maximum and minimum $\delta^{18} \mathrm{O}$ values also decrease between intervals IIA and IIB by 1.4 and $0.5 \%$. Thus, the oxygen isotope data from bulk sampling of tooth enamel shows no evidence of significant change between intervals IIA and IIB.

Previously published $\delta^{18} \mathrm{O}$ data from pedogenic carbonates cannot be split into intervals IIA and IIB due to lack of stratigraphic resolution so the data from each interval cannot be directly compared. Overall the data show an increase in $\delta^{18} \mathrm{O}$ values in the Lemuta Member with respect to Bed I and the lowermost Bed II (Cerling and Hay, 1986; Sikes, 1994). The overall trend towards more positive $\delta^{18} \mathrm{O}$ values, indicative of increased aridity, continues in Upper Bed II through Bed IV and into the Masek and Ndutu Formations.

The intratooth isotope profiles from E. oldowayensis molars are limited in number, so the interpretation of seasonality we draw could change with additional data. Both carbon and oxygen isotopes show greater variation in interval IIA than in IIB (Figure 6). It can therefore be concluded that seasonality of vegetation and rainfall was likely reduced in the IIB interval compared to the IIA interval. 
This study demonstrates that a combined approach of stable isotope and tooth wear analyses can yield more detailed and robust dietary reconstructions than a single method alone. This is most evident for taxa where there are large samples, such as for the Alcelaphini and Equidae, which were determined to be predominantly $\mathrm{C}_{4}$ grazers, with occasional mixed $\mathrm{C}_{3}-\mathrm{C}_{4}$ feeding. It can also help resolve inconsistencies in dietary reconstructions, such for the Reduncini, which yield strong $\mathrm{C}_{4}$ and grazing signals from the isotopes and mesowear but plot as browsers according to mesowear. Some of the inconsistencies may be highlighting actual dietary breadth (e.g., perhaps seasonal) not detected by the application of a single method alone.

\section{Acknowledgements}

Fieldwork in Bed II by OGAP was authorized by the Commission for Science and Technology, the Department of Antiquities, and the Ngorongoro Conservation Area Authority, Tanzania, and funded by the NSF (BCS-0852292) and a European Research Council-Starting Grant (283366). We thank Merve Gumrukcu, Mark Franklin, and Natalia Galud Erazo for assistance with sampling, pretreatment, and weighing of enamel samples for isotope analysis, and Wei Huang for assistance with mass spectrometry. Isotopic and use wear analyses were funded by the ERCStarting Grant (283366), Columbia University's Center for Climate and Life (KTU), and the MINECO grants (HAR2013-48784-C3-1-P and HAR2016-76760-C3-1-P). This is LamontDoherty Earth Observatory contribution \#8XXX.

\section{Figures}

Figure 1. A) Map of Olduvai Gorge with the Bed II sites from which fossil teeth analyzed in this study come from. Interval IIA teeth ( 1.7 Ma) are from the HWK EE, FLK West, and MNK Skull sites; Interval IIB ( 1.66 Ma) teeth are from the HWK EE, HWK E-Tembo, FC West, FC East, and MNK Main sites; Interval Above IIC includes teeth from the FLK West and EF-HR sites. B) A simplified stratigraphic framework based on Hay (1976) and Stanistreet et al. (this volume), following the proposal to use the top of Lemuta to separate Lower Bed II from Middle Bed II (see Stanistreet et al, this volume). Intervals defined in this study are shown in colored boxes. Sampled sites are listed by interval. Tuffs are marked in orange and their ages are from Curtis and Hay (1972), Deino (2012), and Dominguez-Rodrigo et al. (2013). *Approximate age of Bird Print Tuff (BPT) is derived from dating of a tuff denominated FLKWb by Diez-Martin et 
al. (2015), which Uribelarrea et al. (in press) place at $\sim 25 \mathrm{~cm}$ below the level of the BPT nearby. [color, double column]

Figure 2. Cross plot of tooth enamel carbon and oxygen isotopes from the two main Bed II intervals, A) Interval IIB (1.66 Ma) and B) Interval IIA ( 1.7 Ma). Shaded regions indicate $\mathrm{C}_{3^{-}}$ dominated (green, online color version), mixed $\mathrm{C}_{3}-\mathrm{C}_{4}$ (yellow), and $\mathrm{C}_{4}$-dominated (orange) diets based on $\delta^{13} \mathrm{C}$ values. Data are plotted at the family level except for bovids, which are plotted by tribe. For giraffids, the Giraffa sp. has a $\mathrm{C}_{3}$-dominated diet and Sivatherium sp. a $\mathrm{C}_{4}$-dominated diet. [color, single column]

Figure 3. Carbon and oxygen isotope data from the two main Bed II intervals and modern taxa from Tanzania (Van der Merwe, 2013). In all three intervals, mammals with $\mathrm{C}_{4}$-dominated diets are most common with the number of mammals with mixed $\mathrm{C}_{3}-\mathrm{C}_{4}$ and $\mathrm{C}_{3}$-dominated diets varying between intervals. Modern $\delta^{18} \mathrm{O}$ values show the broadest range and have a median value that is $\sim 2 \%$ enriched with respect to Bed II median values (Table 2). Interval IIB includes all Hippopotamidae data $(\mathrm{N}=16)$, whereas for statistical analyses whereas for statistical analyses only the minimum, maximum and median values are used. [color, single column]

Figure 4. Tooth enamel carbon and oxygen isotope box plots by intervals (IIA, IIB, and modern). The vertical gray line in a box is the median, the box ends are the $1^{\text {st }}$ and $3^{\text {rd }}$ quartiles, and lines (whiskers) define the range of data except for outliers. Taxa are divided by at the family level or where possible, by genera. In the Giraffa/Sivatherium panel, Giraffa is in white and Sivatherium is in gray. [color, double column]

Figure 5. Tooth enamel carbon and oxygen isotope box plots for Bed II and modern bovid tribes. All Bovidae data are plotted in the uppermost panel for reference. [color, double column]

Figure 6. Intratooth Equus oldowayensis isotope profiles from interval IIB (MNK Main L1-48 and FC West L62-104; panels A-D) and interval IIA (HWK EE L10-523; panels E \& F). Open circles are measured data (smoothed with a 3 pt. weighted mean; see text for details), the thick line is the mean of 100 inverse model solutions for the estimated input signal (i.e., diet or body water), and the shaded area is \pm 2 个 of the solutions. The IIA interval profile exhibits greater variability than the two profiles from the IIB interval. [color, double column]

Figure 7. Mesowear scores for the taxa from Bed II intervals IIA and IIB. Sample size is given in parenthesis for each taxon. The data from modern browsers, mixed feeders and grazers are taken from Fortelius and Solounias (2000). [color, double column]

Figure 8. Bivariate plot of the average numbers of pits and scratches for the Bovidae (A) and the other taxa (B). Bars correspond to standard deviations for the fossil samples. Grey areas correspond to the Gaussian confidence ellipses $(p=0.95)$ on the centroid for the modern leaf browsers and grazers based on Solounias and Semprebon (2002) and Rivals et al. (2010). [color, single column]

Figure 9. Bivariate plot of the average numbers of pits and scratches for primates (modified from Godfrey et al. 2004) with the three Theropithecus oswaldi specimens from Olduvai Bed II 
intervals IIA and IIB plotted as red stars. T. oswaldi plots among extant primates feeding on grass. [color, single column]

Figure S1. Bar graphs (A, B) and cross plots (C, D) of relative taxonomic abundances of isotope vs. NISP data sets for interval IIA and IIB.

Figure S2. Cross plot of tooth enamel carbon and oxygen isotopes from all sites investigated in this study: A) FLK West, B) EF- HR, C) FC East and West, D) MNK, and E) HWK EE. Shaded regions indicate $\mathrm{C}_{3}$-dominated (green, online color version), mixed $\mathrm{C}_{3}-\mathrm{C}_{4}$ (yellow), and $\mathrm{C}_{4^{-}}$ dominated (orange) diets based on $\delta^{13} \mathrm{C}$ values. Data are plotted at the family level except for bovids, which are plotted by tribe.

Figure S3. Histograms of A) $\delta^{13} \mathrm{C}$ and B) $\delta^{18} \mathrm{O}$ for three forms of Alcelaphini (Megalotragus issaci, Alcelaphini small sp., and Alcelaphini sp. indet) from Bed II. Neither isotope shows niche partitioning among the Alcelaphini. Panels $\mathrm{C}$ ) and $\mathrm{D}$ ) show $\delta^{13} \mathrm{C}$ and $\delta^{18} \mathrm{O}$ for the two Equidae species in Bed II, Equus oldowayensis and Eurygnathohippus cornelianus. The latter tend to have more positive $\delta^{13} \mathrm{C}$ values that indicate a greater proportion of $\mathrm{C}_{4}$ vegetation in their diet although sample size is small $(\mathrm{N}=5)$. There is no difference in $\delta^{18} \mathrm{O}$ values.

\section{Tables}

Table 1. Number of teeth analyzed for carbon and oxygen isotope ratios by mammalian family from intervals IIA, IIB, and above IIC. Bovidae are further specified to tribe.

Table 2. Summary statistics of carbon and oxygen stable isotope data for modern and Bed II taxa. Bed II taxa are divided into the intervals IIA, IIB, and above IIC. Interval IIB does not include all Hippopotamidae as they are overrepresented. Modern enamel $\delta^{13} \mathrm{C}$ values are corrected by $+1.5 \%$ for recent changes to the $\delta^{13} \mathrm{C}$ value of the atmosphere.

Table 3. Mann-Whitney U test results comparing carbon and oxygen isotope distributions between the two main intervals (IIA and IIB) and modern Tanzanian taxa from Van der Merwe (2013). Significant differences in oxygen isotope distributions $(p<0.05)$ are in bold.

Hippopotamidae $(\mathrm{N}=16)$ are over represented in the IIB interval so their values were removed and replaced with the maximum, mean, and median values to represent the group.

Table 4. Summary of mesowear and microwear data for the fossil assemblages from Olduvai Bed II intervals IIA and IIB. Abbreviations: $\mathrm{N}=$ Number of specimens; MWS $=$ Mesowear score; NP = Average number of pits; $\mathrm{NS}=$ Average number of scratches; $\% \mathrm{LP}=$ Percentage of specimens with large pits; $\% \mathrm{G}=$ Percentage of specimens with gouges; $\mathrm{SWS}=$ Scratch width score; $\% \mathrm{XS}=$ Percentage of specimens with cross scratches; $\% \mathrm{HC}=$ Percentage of specimens with hypercoarse scratches; \% $\mathrm{PP}=$ Percentage of specimens with puncture pits; $\mathrm{SD}=$ standard deviation.

Table S1. Calculated $\delta 13 \mathrm{C}$ values for $\mathrm{C} 3$ and $\mathrm{C} 4$ plants and for tooth enamel based on average $\mathrm{C} 3$ plant and $\mathrm{C} 4$ plant diets. The values are based on estimated $813 \mathrm{C}$ values of atmospheric $\mathrm{CO} 2$ ( $813 \mathrm{Catm})$ during Bed II and modern times. The Bed II $\delta 13 \mathrm{Catm}$ value is calculated from 
the mean value from 1.8 to $1.6 \mathrm{Ma}$ from the high resolution planktonic $\mathrm{CO} 2 \delta 13 \mathrm{C}$ record compiled by Tipple et al (2010).

Table S2. Number of specimens and relative abundances (percent) for stable isotope and NISP data sets by interval. NISP values were taken from Bibi et al., this volume.

Table S3. Stable carbon and oxygen isotope information for all samples analyzed in this study. Other data includes taxonomic information, sample location, \%C4 $( \pm 1 \sigma)$ in diet, stratigraphic interval (i.e., IIA), and element sampled.

Table S4. Descriptive statistics for stable isotopes and \%C4 in diet for samples from the primary sample sites of HWKEE, FC East and West, and MNK.

Table S5. Mann-Whitney U test results comparing stable isotope values from the primary sample sites of HWKEE, FC East and West, and MNK. None of the comparisons yield significant values.

Table S6. Intratooth stable isotope and estimated \%C4 $( \pm 1 \sigma)$ data for Equidae molar profiles. Smoothed data (3 pt., weighted 0.25/0.50/0.25) and inverse model results (estimated input signal) are given with $2 \sigma$ uncertainty. Sample locations are given as distance from the occlusal surface. Summary statistics are provided for each intratooth profile. Estimated input signal was calculated using Matlab code modified from "mSolve_1.m" published by Passey et al. (2005).

Table S7. Inverse model error parameters and damping factor (e). The damping factor is determined by matching the predicted error $\left(E_{\text {Pred }}\right)$ to the measured error $\left(E_{\text {meas }}\right)$. $E_{\text {meas }}$ is slope dependent and was calculated using published Matlab code (Emeas_1.m) from Passey et al. (2005).

Table S8. Raw tooth wear data. All mesowear and microwear data from Olduvai Bed II fossil teeth analyzed in this study along with taxonomic, sample, and location data. MWS= Mesowear Score (0-6); NP= number of pits; NS = number of scratches, $\mathrm{LP}=$ large pits; $\mathrm{G}=$ gauges; $\mathrm{SWS}=$ scratch width score; $\mathrm{XS}=$ cross scratches; $\mathrm{PP}=$ puncture pit; $\mathrm{HC}=$ hyper coarse scratches. 


\section{References Cited}

Albert, R., Bamford, M., Stanistreet, I., Stollhofen, H., Rivera-Rondón, C., Rodríguez-Cintas, A., 2015a. Vegetation landscape at DK locality, Olduvai Gorge, Tanzania. Palaeogeography, Palaeoclimatology, Palaeoecology 426, 34-45.

Albert, R.M., Bamford, M.K., 2012. Vegetation during UMBI and deposition of Tuff IF at Olduvai Gorge, Tanzania (ca. 1.8 Ma) based on phytoliths and plant remains. Journal of Human Evolution 63, 342-350.

Albert, R.M., Bamford, M.K., Cabanes, D., 2006. Taphonomy of phytoliths and macroplants in different soils from Olduvai Gorge (Tanzania) and the application to Plio-Pleistocene palaeoanthropological samples. Quaternary International 148, 78-94.

Albert, R.M., Bamford, M.K., Cabanes, D., 2009. Palaeoecological significance of palms at Olduvai Gorge, Tanzania, based on phytolith remains. Quaternary International 193, 41-48.

Albert, R.M., Bamford, M.K., Esteban, I., 2015b. Reconstruction of ancient palm vegetation landscapes using a phytolith approach. Quaternary International 369, 51-66.

Ashley, G.M., Bunn, H.T., Delaney, J.S., Barboni, D., Domínguez-Rodrigo, M., Mabulla, A.Z., Gurtov, A.N., Baluyot, R., Beverly, E.J., Baquedano, E., 2014. Paleoclimatic and paleoenvironmental framework of FLK North archaeological site, Olduvai Gorge, Tanzania. Quaternary International 322, 54-65.

Bamford, M.K., 2012. Fossil sedges, macroplants, and roots from Olduvai Gorge, Tanzania. Journal of Human Evolution 63, 351-363.

Bamford, M.K., Albert, R.M., Cabanes, D., 2006. Plio-Pleistocene macroplant fossil remains and phytoliths from Lowermost Bed II in the eastern palaeolake margin of Olduvai Gorge, Tanzania. Quaternary International 148, 95-112.

Bamford, M.K., Stanistreet, I.G., Stollhofen, H., Albert, R.M., 2008. Late Pliocene grassland from Olduvai Gorge, Tanzania. Palaeogeography, Palaeoclimatology, Palaeoecology 257, 280293.

Barboni, D., Ashley, G.M., Dominguez-Rodrigo, M., Bunn, H.T., Mabulla, A.Z., Baquedano, E., 2010. Phytoliths infer locally dense and heterogeneous paleovegetation at FLK North and surrounding localities during upper Bed I time, Olduvai Gorge, Tanzania. Quaternary Research 74, 344-354. 
Behrensmeyer, A.K., Boaz, D.E.D., 1980. The recent bones of Amboseli Park, Kenya, in relation to East African paleoecology, in: Behrensmeyer, A.K., Hill, A. (Eds.), Fossils in the making: Vertebrate taphonomy and paleoecology. University of Chicago Press, Chicago, p. 72.

Bendrey, R., Vella, D., Zazzo, A., Balasse, M., Lepetz, S., 2015. Exponentially decreasing tooth growth rate in horse teeth: implications for isotopic analyses. Archaeometry 57, 1104-1124.

Blumenthal, S.A., Cerling, T.E., Chritz, K.L., Bromage, T.G., Kozdon, R., Valley, J.W., 2014. Stable isotope time-series in mammalian teeth: in situ $\delta 18 \mathrm{O}$ from the innermost enamel layer. Geochimica Et Cosmochimica Acta 124, 223-236.

Bocherens, H., Koch, P., Mariotti, A., Geraads, D., Jaeger, J., 1996. Isotopic biogeochemistry (13 C, 18 O) of mammalian enamel from African Pleistocene hominid sites. Palaios 11, 306-318.

Bonnefille, R., 1984. Palynological research at Olduvai Gorge. National Geographic Society Research Reports 17, 227-243.

Cerling, T., Harris, J., 1999. Carbon isotope fractionation between diet and bioapatite in ungulate mammals and implications for ecological and paleoecological studies. Oecologia 120, 347-363.

Cerling, T., Harris, J., Leakey, M., Mudidia, N., 2003a. Stable isotope ecology of Northern Kenya, with emphasis on the Turkana Basin, in: Leakey, M.G., Harris, J.M. (Eds.), Lothagam: The Dawn of Humanity in Eastern Africa. Columbia University Press, New York, pp. 583-603.

Cerling, T., Harris, J., Passey, B., 2003b. Diets of East African Bovidae based on stable isotope analysis. Journal of Mammalogy 84, 456-470.

Cerling, T.E., Andanje, S.A., Blumenthal, S.A., Brown, F.H., Chritz, K.L., Harris, J.M., Hart, J.A., Kirera, F.M., Kaleme, P., Leakey, L.N., Leakey, M.G., Levin, N.E., Manthi, F.K., Passey, B.H., Uno, K.T., 2015. Dietary changes of large herbivores in the Turkana Basin, Kenya from 4 to 1 Ma. Proceedings of the National Academy of Sciences.

Cerling, T.E., Chritz, K.L., Jablonski, N.G., Leakey, M.G., Manthi, F.K., 2013. Diet of Theropithecus from 4 to 1 Ma in Kenya. Proceedings of the National Academy of Sciences 110, 10507-10512.

Cerling, T.E., Harris, J.M., Hart, J.A., Kaleme, P., Klingel, H., Leakey, M.G., Levin, N.E., Lewison, R.L., Passey, B.H., 2008. Stable isotope ecology of the common hippopotamus. Journal of Zoology 276, 204-212.

Cerling, T.E., Hay, R.L., 1986. An isotopic study of Paleosol carbonates from Olduvai Gorge. Quaternary Research (New York) 25, 63-78. 
Cerling, T.E., Wynn, J.G., Andanje, S.A., Bird, M.I., Korir, D.K., Levin, N.E., Mace, W., Macharia, A.N., Quade, J., Remien, C.H., 2011. Woody cover and hominin environments in the past 6 million years. Nature 476, 51-56.

Craig, H., 1954. Carbon 13 in plants and the relationships between carbon 13 and carbon 14 variations in nature. The Journal of Geology 62, 115-149.

Curtis, G.H., Hay, R.L., 1972. Further geological studies and potassium-argon dating at Olduvai Gorge and Ngorongoro Crater, in: Bishop, W.W., Miller, J.A. (Eds.), Calibration of Hominoid Evolution. Scottish Academic Press, Edinburgh, pp. 289-302.

Deino, A.L., 2012. 40 Ar/39 Ar dating of Bed I, Olduvai Gorge, Tanzania, and the chronology of early Pleistocene climate change. Journal of Human Evolution 63, 251-273.

Diez-Martín, F., Yustos, P.S., Uribelarrea, D., Baquedano, E., Mark, D., Mabulla, A., Fraile, C., Duque, J., Díaz, I., Pérez-González, A., 2015. The origin of the Acheulean: the 1.7 million-yearold site of FLK West, Olduvai Gorge (Tanzania). Scientific reports 5.

Domínguez-Rodrigo, M., Pickering, T.R., Baquedano, E., Mabulla, A., Mark, D.F., Musiba, C., Bunn, H.T., Uribelarrea, D., Smith, V., Diez-Martin, F., 2013. First partial skeleton of a 1.34million-year-old Paranthropus boisei from Bed II, Olduvai Gorge, Tanzania. PLoS One 8, e80347.

Fortelius, M., Solounias, N., 2000. Functional characterization of ungulate molars using the abrasion-attrition wear gradient: a new method for reconstructing paleodiets. American Museum Novitates 3301, 1-36.

Fox-Dobbs, K., Wheatley, P., Koch, P., 2006. Carnivore specific bone bioapatite and collagen carbon isotope fractionations: case studies of modern and fossil grey wolf populations, AGU Fall Meeting Abstracts.

Fricke, H.C., O'Neil, J.R., 1996. Inter-and intra-tooth variation in the oxygen isotope composition of mammalian tooth enamel phosphate: implications for palaeoclimatological and palaeobiological research. Palaeogeography, Palaeoclimatology, Palaeoecology 126, 91-99.

Gentry, A.W., Gentry, A., 1978. Fossil Bovidae (Mammalia) of Olduvai Gorge, Tanzania. British Museum (Natural History).

Godfrey, L.R., Semprebon, G.M., Jungers, W.L., Sutherland, M.R., Simons, E.L., Solounias, N., 2004. Dental use wear in extinct lemurs: evidence of diet and niche differentiation. Journal of Human Evolution 47, 145-169. 
Habermann, J.M., McHenry, L.J., Stollhofen, H., Tolosana-Delgado, R., Stanistreet, I.G., Deino, A.L., 2016a. Discrimination, correlation, and provenance of Bed I tephrostratigraphic markers, Olduvai Gorge, Tanzania, based on multivariate analyses of phenocryst compositions.

Sedimentary Geology 339, 115-133.

Habermann, J.M., Stanistreet, I.G., Stollhofen, H., Albert, R.M., Bamford, M.K., Pante, M.C., Njau, J.K., Masao, F.T., 2016b. In situ 2.0 Ma trees discovered as fossil rooted stumps, lowermost Bed I, Olduvai Gorge, Tanzania. Journal of Human Evolution 90, 74-87.

Harris, J., Cerling, T., 2002. Dietary adaptations of extant and Neogene African suids. Journal of Zoology 256, 45-54.

Hay, R.L., 1963. Stratigraphy of Beds I through IV, Olduvai Gorge, Tanganyika. Science 139, 829-833.

Hay, R.L., 1976. Geology of the Olduvai Gorge. University of California Press, Berkeley.

Hoppe, K.A., Stover, S.M., Pascoe, J.R., Amundson, R., 2004a. Tooth enamel biomineralization in extant horses: implications for isotopic microsampling. Palaeogeography, Palaeoclimatology, Palaeoecology 206, 355-365.

Hoppe, K.A., Stover, S.M., Pascoe, J.R., Amundson, R., 2004b. Tooth enamel biomineralization in extant horses: implications for isotopic microsampling. Palaeogeography, Palaeoclimatology, Palaeoecology 206, 355-365.

Jones, M., Milburn, T., 1978. Photosynthesis in papyrus (Cyperus papyrus L.). Photosynthetica, 197-199.

Kaiser, T.M., 2011. Feeding ecology and niche partitioning of the Laetoli ungulate faunas, in: Harrison, T. (Ed.), Paleontology and geology of Laetoli: Human evolution in context. Springer, New York, pp. 329-354.

Kappelman, J., 1984. Plio-Pleistocene environments of Bed I and Lower Bed II, Olduvai Gorge, Tanzania. Palaeogeography, Palaeoclimatology, Palaeoecology 48, 171-196.

Kingston, J.D., 2011. Stable isotopic analyses of Laetoli fossil herbivores, in: Harrison, T. (Ed.), Paleontology and geology of Laetoli: Human evolution in context. Springer, New York, pp. 293328.

Kingston, J.D., Harrison, T., 2007. Isotopic dietary reconstructions of Pliocene herbivores at Laetoli: Implications for early hominin paleoecology. Palaeogeography, Palaeoclimatology, Palaeoecology 243, 272-306. 
Kohn, M.J., Schoeninger, M.J., Valley, J.W., 1996. Herbivore tooth oxygen isotope compositions: effects of diet and physiology. Geochimica Et Cosmochimica Acta 60, 3889-3896.

Kovarovic, K., Slepkov, R., McNulty, K.P., 2013. Ecological continuity between lower and upper bed II, Olduvai Gorge, Tanzania. Journal of Human Evolution 64, 538-555.

Leakey, L.S., 1959. A new fossil skull from Olduvai. Nature 184, 491-493.

Leakey, L.S., Tobias, P.V., Napier, J.R., 1964. A new species of the genus Homo from Olduvai Gorge. na.

Leakey, M.D., 1971. Olduvai Gorge. Vol. 3, Excavations in Beds I and II, 1960-63. Cambridge University Press.

Levin, N.E., Cerling, T.E., Passey, B.H., Harris, J.M., Ehleringer, J.R., 2006. A stable isotope aridity index for terrestrial environments. Proceedings of the National Academy of Sciences of the United States of America 93, 11201-11205.

Livingstone, D., Clayton, W., 1980. An altitudinal cline in tropical African grass floras and its paleoecological significance. Quaternary Research 13, 392-402.

Luz, B., Kolodny, Y., Horowitz, M., 1984. Fractionation of oxygen isotopes between mammalian bone-phosphate and environmental drinking water. Geochimica Et Cosmochimica Acta 48, 1689-1693.

Magill, C.R., Ashley, G.M., Domínguez-Rodrigo, M., Freeman, K.H., 2016. Dietary options and behavior suggested by plant biomarker evidence in an early human habitat. Proceedings of the National Academy of Sciences, 201507055.

Magill, C.R., Ashley, G.M., Freeman, K.H., 2013a. Ecosystem variability and early human habitats in eastern Africa. Proceedings of the National Academy of Sciences 110, 1167-1174.

Magill, C.R., Ashley, G.M., Freeman, K.H., 2013b. Water, plants, and early human habitats in eastern Africa. Proceedings of the National Academy of Sciences 110, 1175-1180.

Manega, P.C., 1993. Geochronology, geochemistry and isotopic study of the Plio-Pleistocene hominid sites and the Ngorongoro volcanic highland in northern Tanzania. University of Colorado, Boulder, Boulder, CO, p. 382.

McHenry, L.J., 2012. A revised stratigraphic framework for Olduvai Gorge Bed I based on tuff geochemistry. Journal of Human Evolution 63, 284-299. 
McHenry, L.J., Njau, J.K., de la Torre, I., Pante, M.C., 2016. Geochemical "fingerprints" for Olduvai Gorge Bed II tuffs and implications for the Oldowan-Acheulean transition. Quaternary Research 85, 147-158.

Metcalfe, J.Z., Longstaffe, F.J., Ballenger, J.A.M., Haynes Jr, C.V., 2011. Isotopic paleoecology of Clovis mammoths from Arizona. Proceedings of the National Academy of Sciences 108, 17916-17920.

Mihlbachler, M.C., Rivals, F., Solounias, N., Semprebon, G.M., 2011. Dietary change and evolution of horses in North America. Science 331, 1178-1181.

Nelson, S.V., 2005. Paleoseasonality inferred from equid teeth and intra-tooth isotopic variability. Palaeogeography, Palaeoclimatology, Palaeoecology 222, 122-144.

Passey, B.H., Cerling, T.E., 2002. Tooth enamel mineralization in ungulates; implications for recovering a primary isotopic time-series. Geochimica Et Cosmochimica Acta 66, 3225-3234.

Passey, B.H., Cerling, T.E., Levin, N.E., 2007. Temperature dependence of oxygen isotope acid fractionation for modern and fossil tooth enamels. Rapid communications in mass spectrometry 21, 2853-2859.

Passey, B.H., Cerling, T.E., Schuster, G.T., Robinson, T.F., Roeder, B.L., Krueger, S.K., 2005. Inverse methods for estimating primary input signals from time-averaged isotope profiles. Geochimica Et Cosmochimica Acta 69, 4101-4116.

Patterson, D., Braun, D., Behrensmeyer, A., Merritt, S., Zliobaite, I., Reeves, J., Wood, B., Fortelius, M., Bobe, R., 2017. Ecosystem evolution and hominin paleobiology at East Turkana, northern Kenya between 2.0 and 1.4 Ma. Palaeogeography, Palaeoclimatology, Palaeoecology in press.

Plummer, T.W., Bishop, L.C., 1994. Hominid paleoecology at Olduvai Gorge, Tanzania as indicated by antelope remains. Journal of Human Evolution 27, 47-75.

Reck, H., 1928. Pelorovis oldowayensis $\mathrm{n}$ gn sp. Wissenschaftliche Ergebnisse der OldowayExpedition 1913, 57-67.

Reck, H., 1951. A preliminary survey of the tectonics and stratigraphy of Olduvai, Olduvai Gorge: A Report on the Evolution of the Hand-axe Culture in Beds I-IV. Cambridge University Press, London, pp. 5-19.

Rivals, F., Mihlbachler, M.C., Solounias, N., 2007. Effect of ontogenetic-age distribution in fossil samples on the interpretation of ungulate paleodiets using the mesowear method. Journal of Vertebrate Paleontology 27, 763-767. 

D.C., 2010. Palaeoecology of the Mammoth Steppe fauna from the late Pleistocene of the North Sea and Alaska: Separating species preferences from geographic influence in paleoecological dental wear analysis. Palaeogeography, Palaeoclimatology, Palaeoecology 286, 42-54.

Rossouw, L., Scott, L., 2011. Phytoliths and pollen, the microscopic plant remains in Pliocene volcanic sediments around Laetoli, Tanzania, in: Harrison, T. (Ed.), Paleontology and geology of Laetoli: Human evolution in context. Springer, New York, pp. 201-215.

Sage, R.F., Sage, T.L., Pearcy, R.W., Borsch, T., 2007. The taxonomic distribution of C4 photosynthesis in Amaranthaceae sensu stricto. American Journal of Botany 94, 1992-2003.

Semprebon, G.M., Godfrey, L.R., Solounias, N., Sutherland, M.R., Jungers, W.L., 2004. Can low-magnification stereomicroscopy reveal diet? Journal of Human Evolution 47, 115-144.

Sharp, Z.D., Cerling, T.E., Cerling, T.E., Harris, J.M., MacFadden, B.J., 1998. Fossil isotope records of seasonal climate and ecology; straight from the horse's mouth Carbon isotopes, diets of North American equids, and the evolution of North American C $<$ sub $>4</$ sub $>$ grasslands. Geology 26, 219-222.

Sikes, N., 1994. Early hominid habitat preferences in East Africa: paleosol carbon isotopic evidence. Journal of Human Evolution 27, 25-45.

Sikes, N.E., Ashley, G.M., 2007. Stable isotopes of pedogenic carbonates as indicators of paleoecology in the Plio-Pleistocene (upper Bed I), western margin of the Olduvai Basin, Tanzania. Journal of Human Evolution 53, 574-594.

Solounias, N., Semprebon, G., 2002. Advances in the reconstruction of ungulate ecomorphology with application to early fossil equids. American Museum Novitates 3366, 1-49.

Souron, A., Boisserie, J.R., White, T.D., 2015. A new species of the suid genus Kolpochoerus from Ethiopia. Acta Palaeontologica Polonica 60, 18.

Suga, S., 1979. Comparative Histology of Progressive Mineralization Pattern of Developing Incisor Enamel of Rodents. Journal of Dental Research 58, 1025-1026.

Swart, P.K., Burns, S.J., Leder, J.J., 1991. Fractionation of the stable isotopes of oxygen and carbon in carbon dioxide during the reaction of calcite with phosphoric acid as a function of temperature and technique. Chemical Geology: Isotope Geoscience section 86, 89-96.

Tieszen, L.L., Senyimba, M.M., Imbamba, S.K., Troughton, J.H., 1979. The distribution of C3 and $\mathrm{C} 4$ grasses and carbon isotope discrimination along an altitudinal and moisture gradient in Kenya. Oecologia 37, 337-350. 
Tipple, B., Meyers, S., Pagani, M., 2010. Carbon isotope ratio of Cenozoic CO2: A comparative evaluation of available geochemical proxies. Paleoceanography 25.

Uno, K.T., Cerling, T.E., Harris, J.M., Kunimatsu, Y., Leakey, M.G., Nakatsukasa, M., Nakaya, H., 2011. Late Miocene to Pliocene carbon isotope record of differential diet change among East African herbivores. Proceedings of the National Academy of Sciences 108, 6509-6514.

Uno, K.T., Polissar, P.J., Jackson, K.E., 2016. Neogene biomarker record of vegetation change in eastern Africa. Proceedings of the National Academy of Sciences 113, 6355-6363.

Uno, K.T., Quade, J., Fisher, D.C., Wittemyer, G., Douglas-Hamilton, I., Andanje, S., Omondi, P., Litoroh, M., Cerling, T.E., 2013. Bomb-curve radiocarbon measurement of recent biologic tissues and applications to wildlife forensics and stable isotope (paleo) ecology. Proceedings of the National Academy of Sciences 110, 11736-11741.

Van der Merwe, N.J., 2013. Isotopic ecology of fossil fauna from Olduvai Gorge at ca 1.8 Ma, compared with modern fauna. South African Journal of Science 109, 1-14.

van der Merwe, N.J., Masao, F.T., Bamford, M.K., 2008. Isotopic evidence for contrasting diets of early hominins Homo habilis and Australopithecus boisei of Tanzania. South African Journal of Science 104, 153-155.

Young, H.J., Young, T.P., 1983. Local Distribution of $\mathrm{C}_{3}$ and $\mathrm{C}_{4}$ Grasses in Sites of Overlap on Mount Kenya. Oecologia 58, 373-377.

Zazzo, A., Bendrey, R., Vella, D., Moloney, A., Monahan, F., Schmidt, O., 2012. A refined sampling strategy for intra-tooth stable isotope analysis of mammalian enamel. Geochimica Et Cosmochimica Acta. 
Table 1.

\begin{tabular}{lrrr}
\hline \multicolumn{1}{c}{ Family } & Tuff IIA & Tuff IIB & $\begin{array}{c}\text { Above } \\
\text { Tuff IIC }\end{array}$ \\
\hline Bovidae & & & \\
$\quad$ Alcelaphini & 17 & 16 & -- \\
$\quad$ Antilopini & 7 & -- & 1 \\
$\quad$ /Aepycerotini & 1 & -- & -- \\
$\quad$ Bovini & 4 & 2 & -- \\
$\quad$ Hippotragini & 3 & 1 & -- \\
$\quad$ Reduncini & 2 & 4 & -- \\
$\quad$ Tragelaphini & 2 & -- & -- \\
$\quad$ Indet. & 1 & 3 & -- \\
Cercopithecidae & 2 & -- & -- \\
Deinotheriidae & -- & 1 & -- \\
Elephantidae & 9 & 11 & 4 \\
Equidae & 1 & -- & 1 \\
Giraffidae (Giraffa) & 2 & 3 & - \\
Giraffidae (Sivatherium $)$ & 1 & 3 & -- \\
Hyaenidae & 2 & 16 & -- \\
Hippopotamidae & 5 & 2 & -- \\
Rhinocerotidae & 4 & 10 & - \\
Suidae & $\mathbf{6 3}$ & $\mathbf{7 2}$ & $\mathbf{6}$ \\
Total & & &
\end{tabular}


Table 2.

\begin{tabular}{|c|c|c|c|c|c|c|c|c|c|c|c|c|}
\hline \multirow[b]{2}{*}{ Interval } & \multirow[b]{2}{*}{$\mathrm{N}$} & \multicolumn{3}{|c|}{$\% \mathrm{C} 4$} & \multicolumn{4}{|c|}{$\delta^{13} \mathrm{C}$} & \multicolumn{4}{|c|}{$\delta^{18} O$} \\
\hline & & median & $\max$ & $\min$ & median & $\max$ & $\min$ & range & median & $\max$ & $\min$ & range \\
\hline Modern & 72 & 69 & 100 & 0 & 0.3 & 4.0 & -15.3 & 19.3 & 2.0 & 6.6 & -4.2 & 10.8 \\
\hline Above IIC & 6 & 94 & 100 & 15 & 2.0 & 3.3 & -9.7 & 13.0 & -0.6 & 2.1 & -2.0 & 4.1 \\
\hline Tuff IIB & 59 & 88 & 100 & 23 & 1.0 & 4.1 & -8.5 & 12.6 & 0.2 & 3.7 & -4.3 & 8.0 \\
\hline Tuff IIA & 63 & 86 & 100 & 0 & 0.7 & 3.3 & -12.9 & 16.2 & 0.2 & 5.1 & -3.8 & 8.9 \\
\hline
\end{tabular}


Table 3

Intervals IIA and IIB Interval IIB and Modern Interval IIA and Modern

All taxa

$\begin{array}{cccc}\text { Carbon } p \text {-value } & 0.5557 & 0.6201 & 0.9613 \\ \text { Oxygen } p \text {-valur } & 0.4607 & \mathbf{0 . 0 0 0 1} & \mathbf{0 . 0 0 1 5} \\ \mathrm{N} & 63 / 59 & 59 / 72 & 63 / 72\end{array}$

Alcelaphini

$\begin{array}{cc}\text { Carbon } p \text {-value } & 0.8451 \\ \text { Oxygen } p \text {-valur } & \mathbf{0 . 0 4 4 5} \\ \mathrm{N} & 17 / 16\end{array}$

Equidae

$\begin{array}{cc}\text { Carbon } p \text {-value } & 0.1754 \\ \text { Oxygen } p \text {-valur } & 0.3312 \\ \mathrm{~N} & 9 / 11\end{array}$


Table 4.

\begin{tabular}{|c|c|c|c|c|c|c|c|c|c|c|c|c|c|c|c|}
\hline \multirow[b]{2}{*}{ Stratigraphy } & \multirow[b]{2}{*}{ Taxa } & \multicolumn{3}{|c|}{ MESOWEAR } & \multicolumn{11}{|c|}{ MICROWEAR } \\
\hline & & $\mathbf{N}$ & MWS & $S D$ & & $\mathbf{N} \mathbf{N F}$ & $\begin{array}{l}S L \\
(\Lambda\end{array}$ & P) & $\begin{array}{l}S D \\
(N S)\end{array}$ & $\% L P$ & $\% G$ & SWS & $\% \mathrm{XS}$ & $\%$ PP & P \%HC \\
\hline & & 13 & 2.00 & 1.53 & 11 & 22.41 & 8.43 & 16.50 & 5.94 & 27.27 & 18.18 & 1.0 & 0.00 & 0.00 & 0.00 \\
\hline \multirow{6}{*}{ Interval IIA } & Caprini & & & & 1 & 9.00 & & 12.50 & & 0.00 & 0.00 & 1.0 & 0.00 & 0.00 & 0.00 \\
\hline & Hippotragini & & 2.50 & 1.00 & 3 & 19.83 & 7.52 & 17.67 & 2.47 & 33.33 & 0.00 & 1.3 & 0.00 & 0.00 & 33.33 \\
\hline & & 2 & 1.00 & & 1 & & & & & 100.00 & 0.00 & & 0.00 & 0.00 & 0.00 \\
\hline & Tragelaphini & & & & & 33.00 & & 10.50 & & & & 1.0 & & & \\
\hline & Alcelaphini & 45 & 2.69 & 1.14 & 35 & 17.50 & 4.82 & 17.66 & 3.09 & 28.57 & 0.00 & 1.2 & 2.86 & 2.86 & 34.29 \\
\hline & $\begin{array}{l}\text { Equus } \\
\text { oldowayensis }\end{array}$ & 10 & 4.40 & 1.35 & 18 & 15.92 & 4.75 & 15.92 & 2.32 & 5.56 & 5.56 & 1.2 & 0.00 & 0.00 & 16.67 \\
\hline
\end{tabular}




\begin{tabular}{|c|c|c|c|c|c|c|c|c|c|c|c|c|c|c|c|}
\hline & $\begin{array}{l}\text { Eurygnathohippus } \\
\text { cornelianus }\end{array}$ & 1 & 4.00 & & 5 & 13.50 & 4.95 & 19.25 & 1.71 & 0.00 & 0.00 & 1.0 & 0.00 & 0.00 & 0.00 \\
\hline & $\begin{array}{l}\text { Sivatherium } \\
\text { maurusium }\end{array}$ & 3 & 2.33 & & 3 & 30.00 & & 14.00 & & 33.33 & 33.33 & 2.0 & 33.33 & 0.00 & 33.33 \\
\hline & \multicolumn{4}{|c|}{ Hippopotamus gorgops } & 3 & 10.17 & & 18.83 & & 33.33 & 33.33 & 1.0 & 100.00 & 0.00 & 0.00 \\
\hline & \multicolumn{4}{|l|}{ Kolpochoerus sp. } & 11 & 18.00 & 5.77 & 20.32 & 2.75 & 63.64 & 18.18 & 1.0 & 90.91 & 18.18 & 0.00 \\
\hline & \multicolumn{4}{|l|}{$\begin{array}{l}\text { Metridiochoerus } \\
\text { sp. }\end{array}$} & 2 & 10.50 & & 17.25 & & 50.00 & 50.00 & 1.0 & 100.00 & 50.00 & 50.00 \\
\hline \multirow{5}{*}{ Interval IIB } & Hippotragini & 3 & 3.67 & & 2 & 15.00 & & 16.50 & & 0.00 & 0.00 & 1.0 & 0.00 & 0.00 & 0.00 \\
\hline & Reduncini & 2 & 0.50 & & 1 & 14.50 & & 20.00 & & 0.00 & 0.00 & 1.0 & 0.00 & 0.00 & 0.00 \\
\hline & Tragelaphini & 1 & 2.00 & & & & & & & & & & & & \\
\hline & Alcelaphini & 38 & 3.34 & 1.21 & 40 & 16.38 & 6.66 & 17.59 & 3.92 & 20.00 & 7.50 & 1.0 & 0.00 & 2.50 & 2.50 \\
\hline & $\begin{array}{l}\text { Equus } \\
\text { oldowayensis }\end{array}$ & 19 & 4.58 & 1.12 & 32 & 15.92 & 4.29 & 18.17 & 2.96 & 40.63 & 9.38 & 1.0 & 6.25 & 0.00 & 0.00 \\
\hline
\end{tabular}




\begin{tabular}{|c|c|c|c|c|c|c|c|c|c|c|c|c|c|c|c|}
\hline & $\begin{array}{l}\text { Eurygnathohippus } \\
\text { cornelianus }\end{array}$ & 5 & 5.20 & 1.10 & 8 & 16.81 & 6.60 & 20.06 & 1.97 & 12.50 & 0.00 & 1.4 & 0.00 & 0.00 & 12.50 \\
\hline & $\begin{array}{l}\text { Sivatherium } \\
\text { maurusium }\end{array}$ & 1 & 4.00 & & 2 & 15.25 & & 12.50 & & 0.00 & 0.00 & 1.0 & 0.00 & 0.00 & 0.00 \\
\hline & $\begin{array}{l}\text { Hippopotamus } \\
\text { gorgops }\end{array}$ & 3 & 4.67 & & 18 & 10.47 & 3.58 & 15.47 & 2.73 & 22.22 & 11.11 & 1.7 & 94.44 & 0.00 & 5.56 \\
\hline & Kolpochoerus sp. & & & & 14 & 16.18 & 6.26 & 17.82 & 4.77 & 21.43 & 21.43 & 1.1 & 92.86 & 0.00 & 14.29 \\
\hline & $\begin{array}{l}\text { Metridiochoerus } \\
\text { sp. }\end{array}$ & & & & 5 & 13.40 & 2.22 & 18.30 & 2.71 & 0.00 & 0.00 & 1.2 & 100.00 & 0.00 & 20.00 \\
\hline & Elephas recki & & & & 1 & 17.00 & & 16.00 & & 0.00 & 0.00 & 2.0 & 0.00 & 0.00 & 0.00 \\
\hline Intervals IIA+IIB & $\begin{array}{l}\text { Theropithecus } \\
\text { oswaldi }\end{array}$ & & & & 3 & 14.67 & & 26.00 & & 33.33 & 0.00 & 1.3 & 66.67 & 0.00 & 0.00 \\
\hline
\end{tabular}




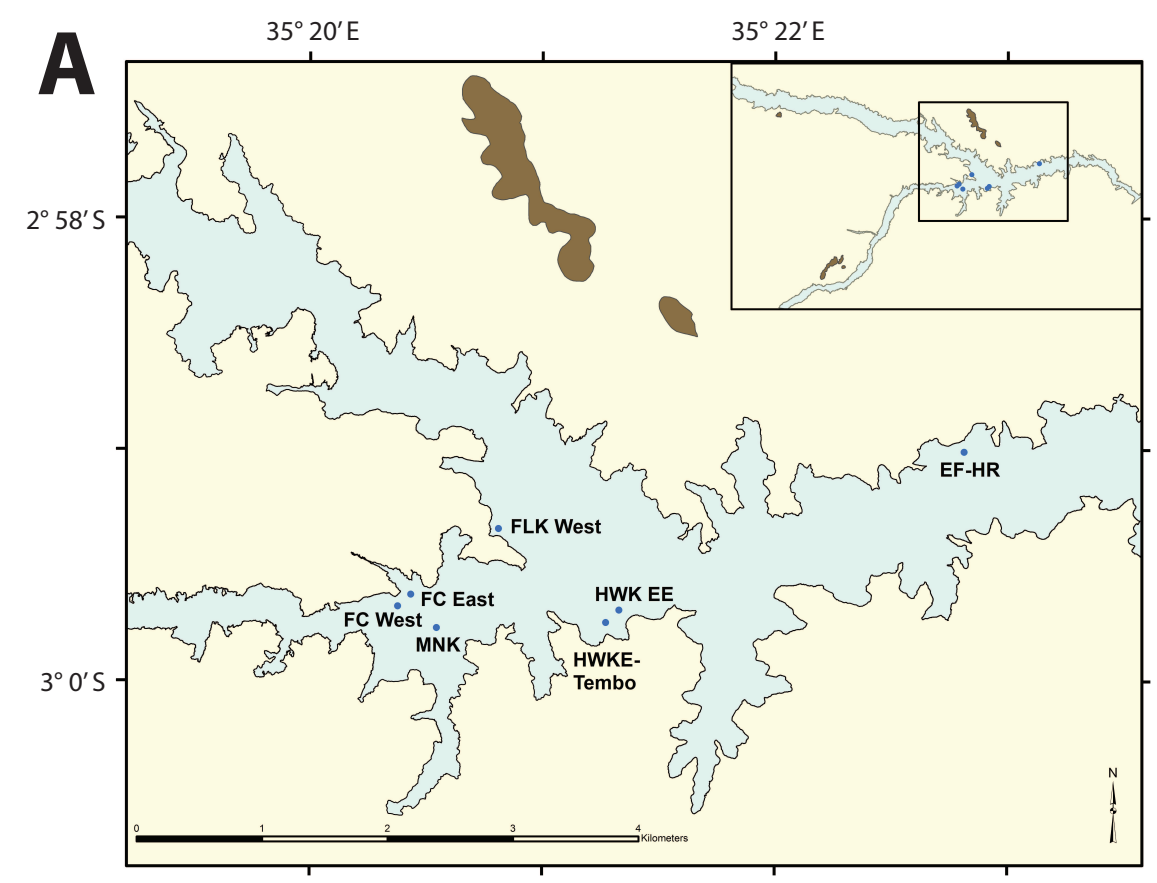

B

Formation Member Locality Tuff + Age $(\mathrm{Ma})$

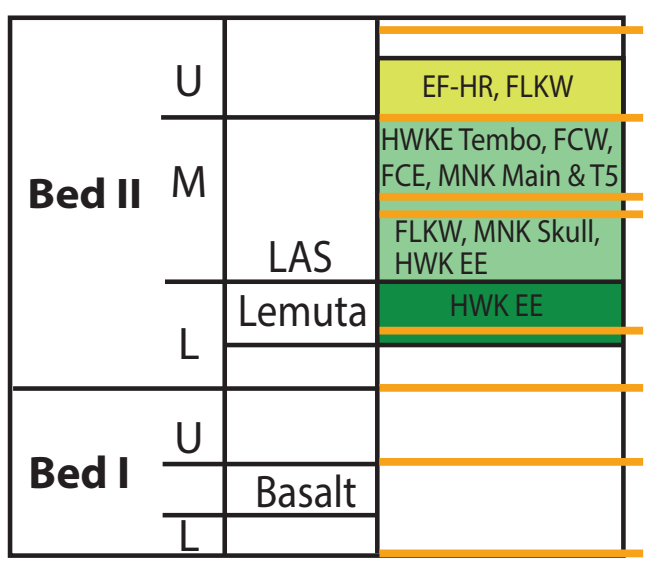

IID 1.34

IIC

BPT $1.66^{*}$

IIB

IIA 1.71

IF 1.80

IB 1.85

Naabi 2.04

\begin{tabular}{|l|l|l|}
\hline Interval IIA Interval IIB Interval IIC \\
\hline
\end{tabular} 


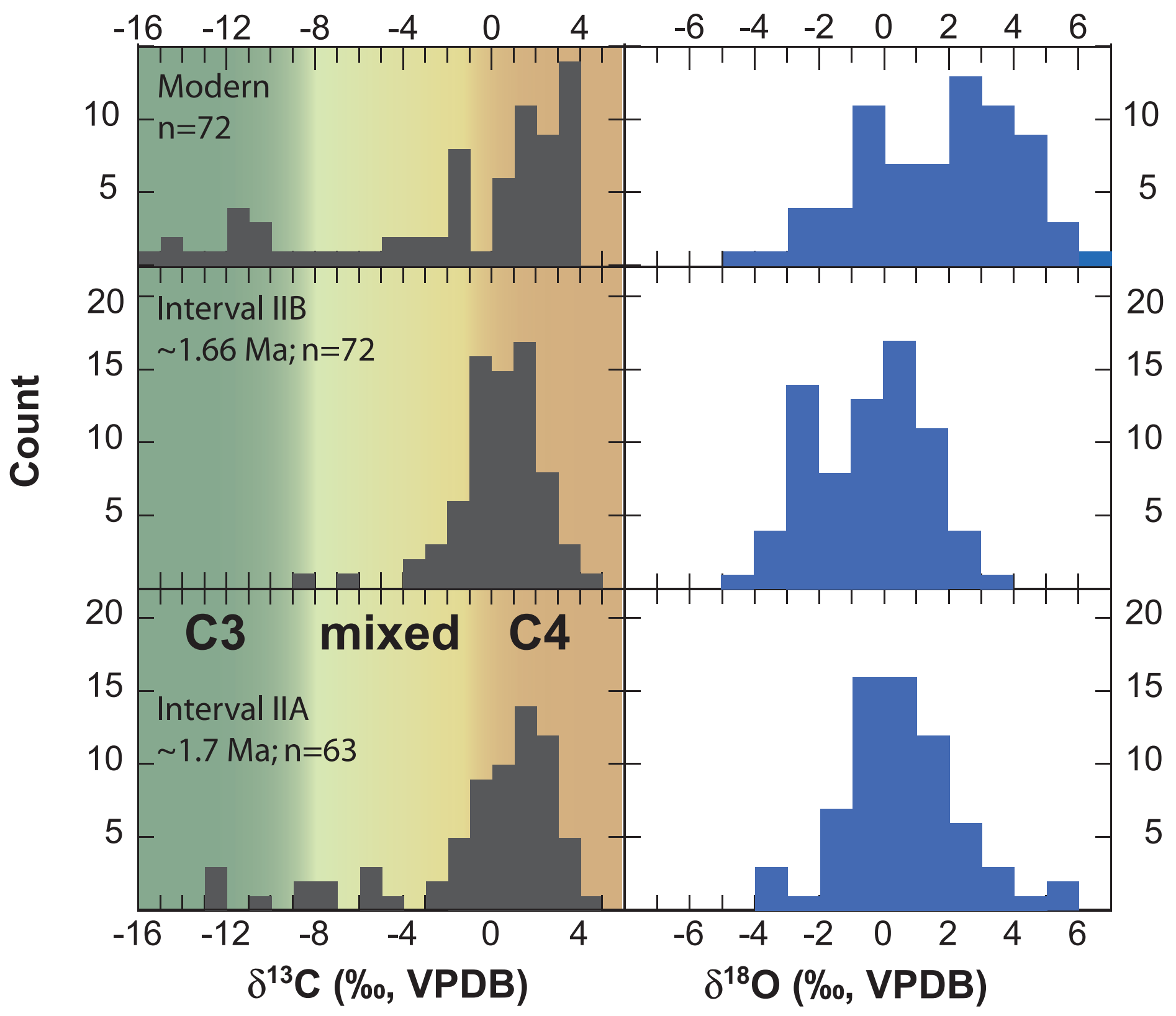




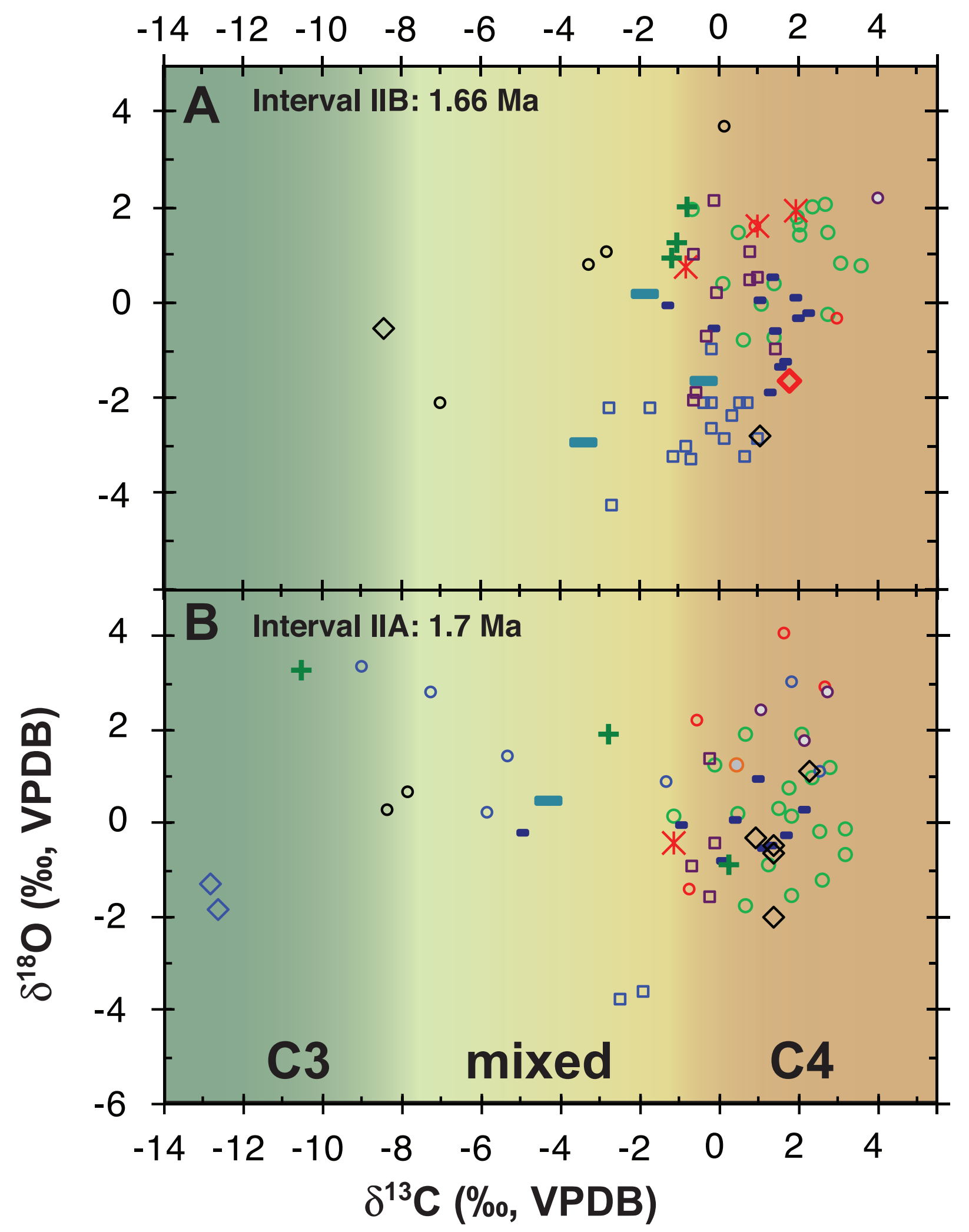

\begin{tabular}{|llllll|}
\hline$\circ$ Alcelaphini & $\circ$ & Reduncini & $\square$ Suidae & $\diamond$ Elephantidae \\
$\circ$ Antilopini & $\circ$ & Tragelaphini & $\bullet$ Equidae & $\diamond$ Deinotheriidae \\
$\circ$ Bovini & + Giraffidae & $\diamond$ Rhinocerotidae & $*$ Cercopithecidae \\
$\circ$ & Hippotragini & $\square$ & Hippopotamidae & - Hyaenidae & \\
\hline
\end{tabular}




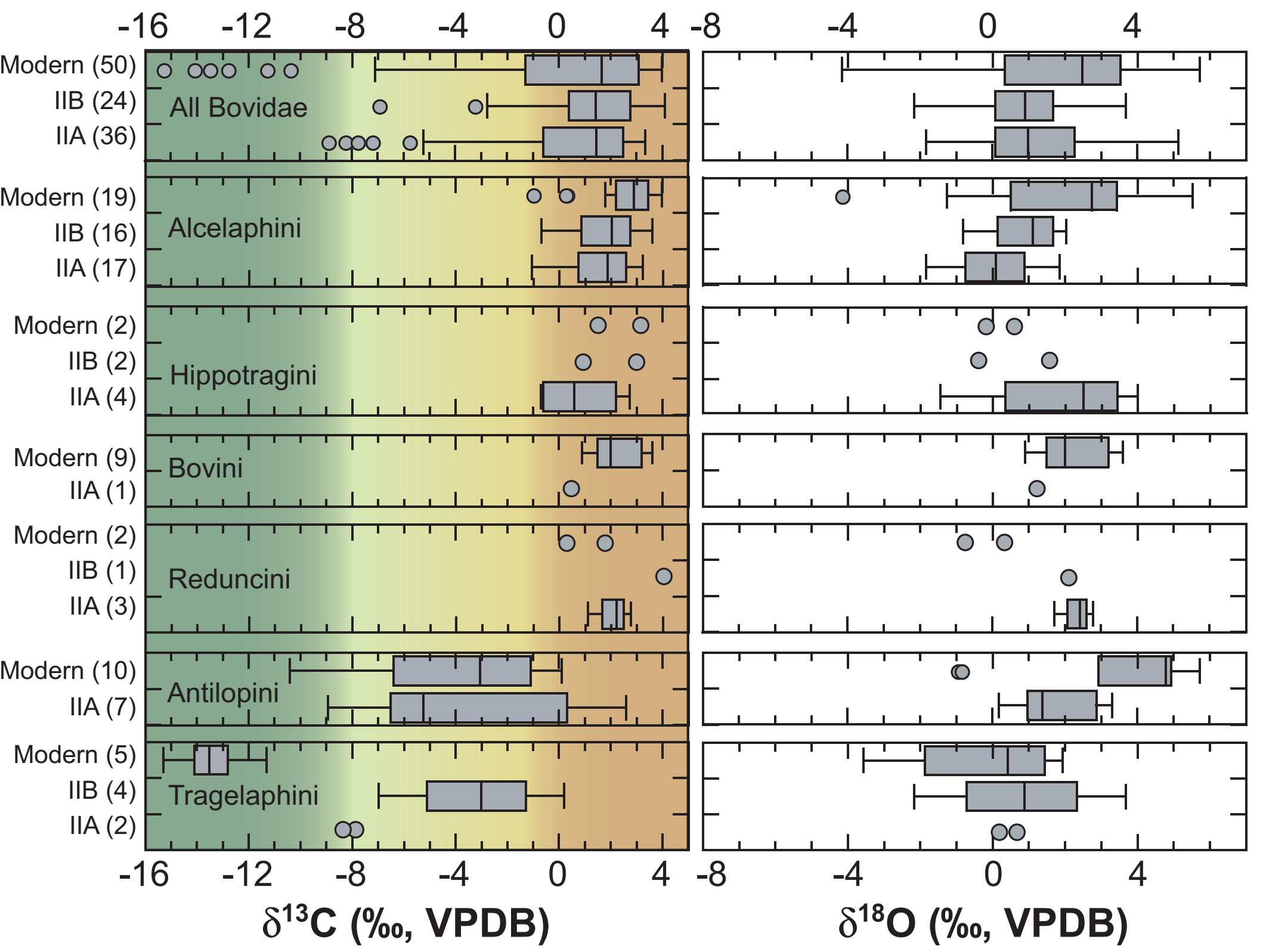



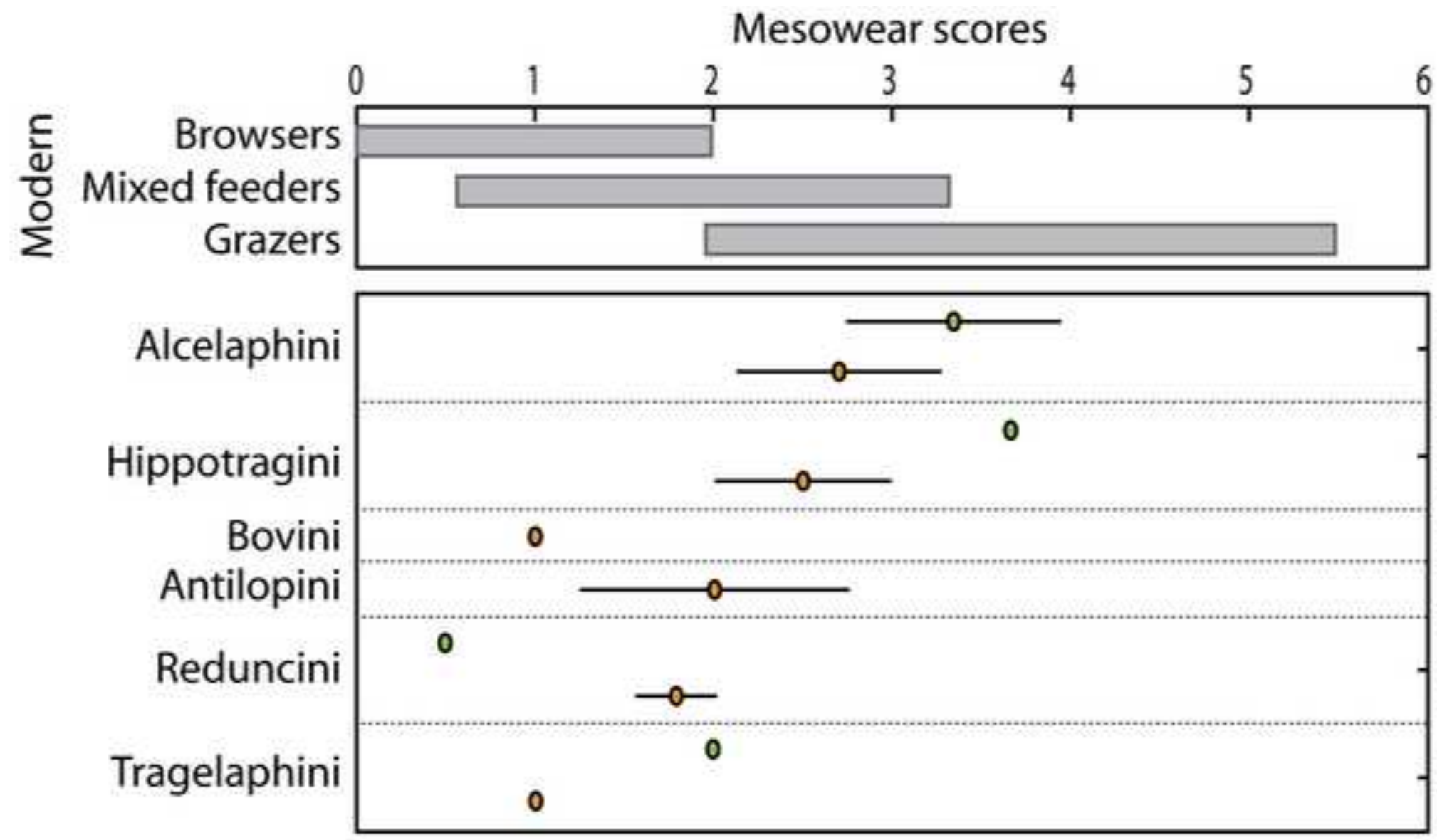

IIB (38)

IIA (45)

IIB (3)

IIA (4)

IIA (1)

IIA (13)

IIB (2)

IIA (5)

IIB (2)

IIA (1)

Sivatherium

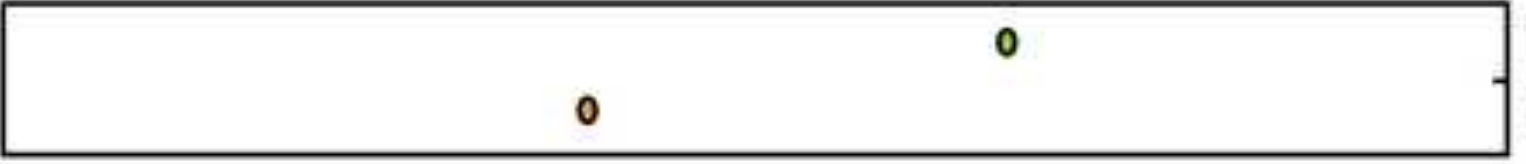

IIB (1)

IIA (3)

H. cf.gorgops

0

IIB (3)

Equus oldowayensis

Eurygnathohippus

cf. cornelianus
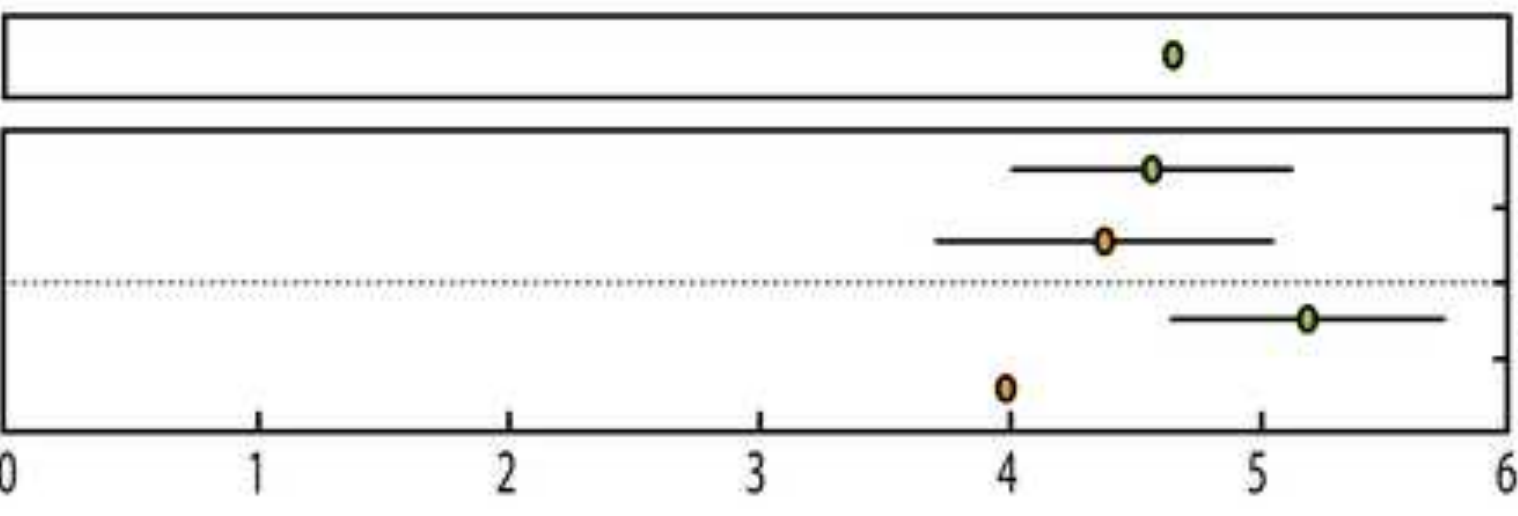

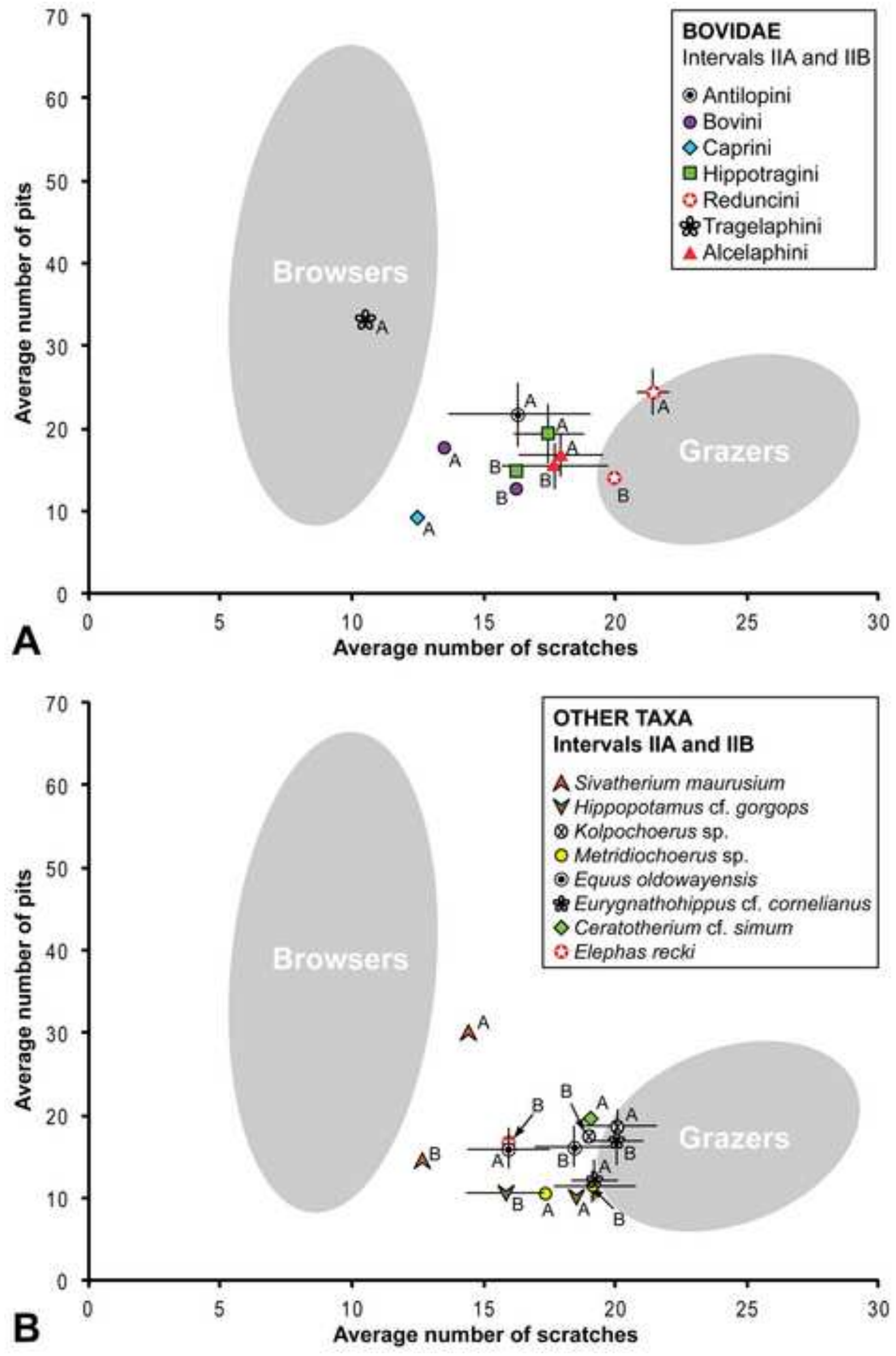


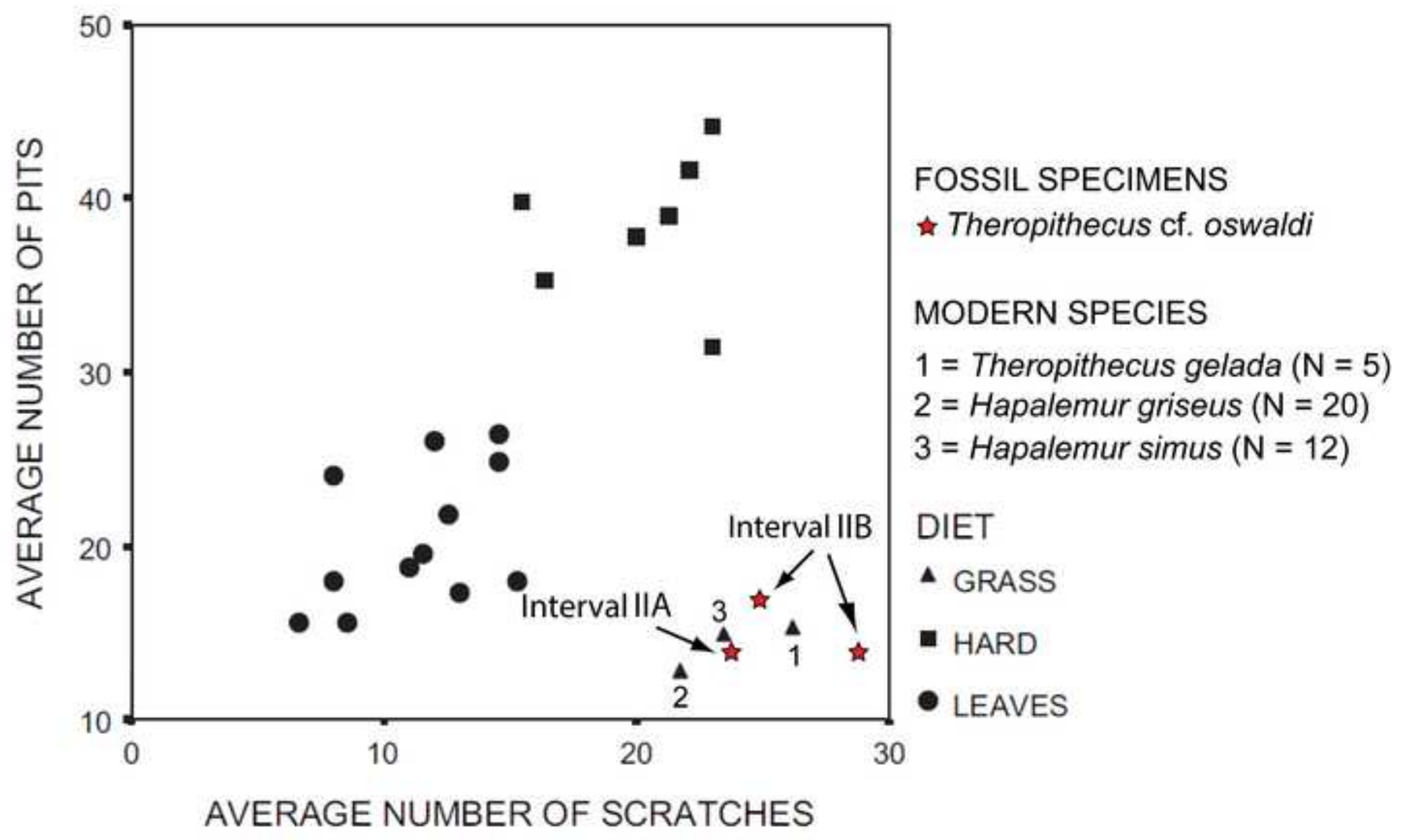


Supplementary Material

Click here to download Supplementary Material: Fig S1 NISP vs Isotope abundances.eps

\author{
-
}

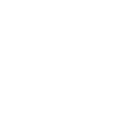

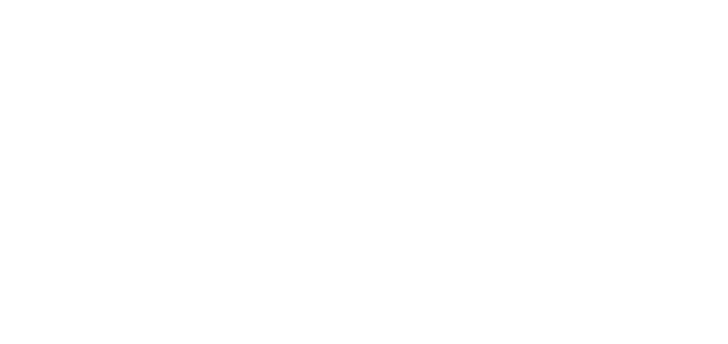
(1) (1) $x^{2}$ $x^{2}$ . (1) (1) (1) (1) (1) (1) (2) (2) (2) (2) (1)

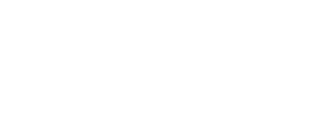

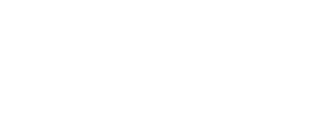

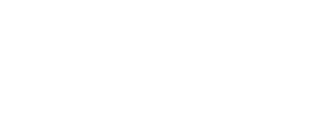

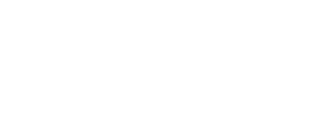

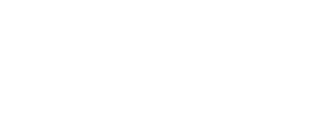

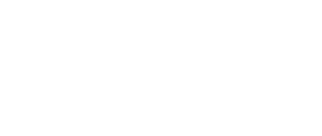

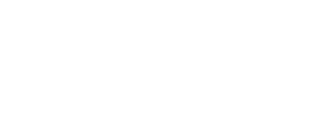
(2) (2)

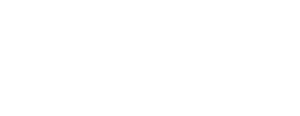


Supplementary Material

Click here to download Supplementary Material: Fig S2 cross plots by site.eps

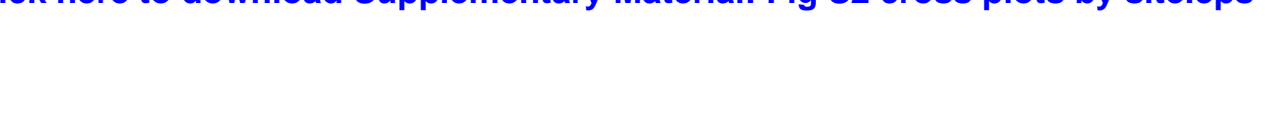

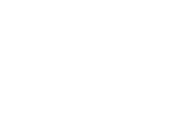

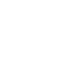

$\sqrt{2}$

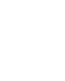

(1)

$\sqrt{3}$ (1) (1) (1) (1)

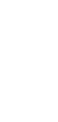

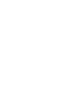

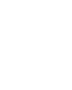

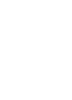

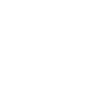

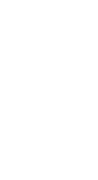

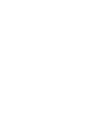

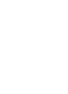

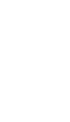

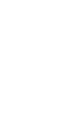
. . . .

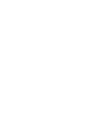
.

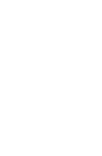

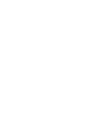

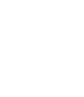

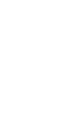

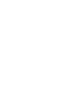

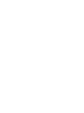

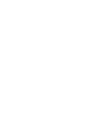

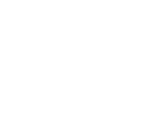

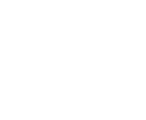

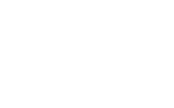
(1) (1) . . . . . . 
Supplementary Material
Click here to download Supplementary Material: Fig S3 AI \& Eq histograms.ep

Supplementary Material
Click here to download Supplementary Material: Fig S3 Al \& Eq histograms.eps

Click here to download Supplementary Material: Fig S3 Al \& Eq histograms.eps

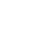

(1)

(1)

(1)

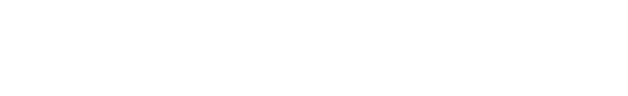

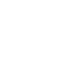

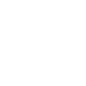

.

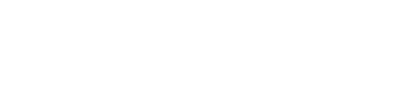

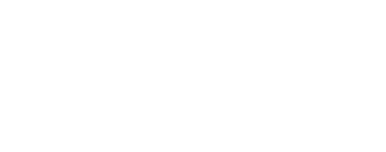

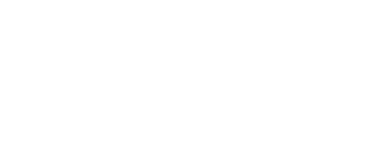

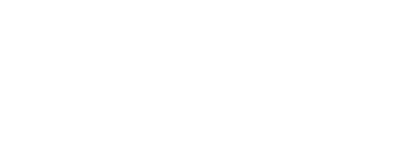

.

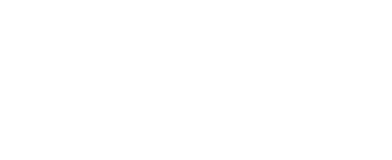

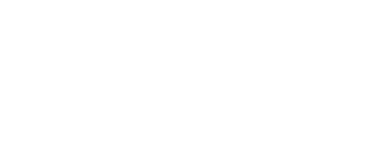

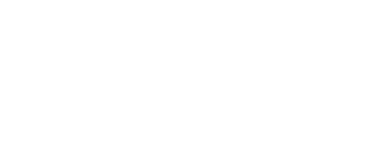

(1)

(1)

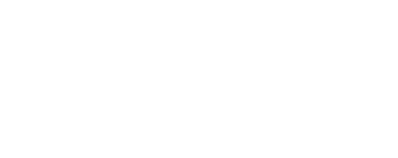

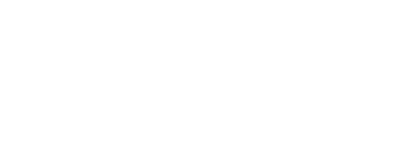

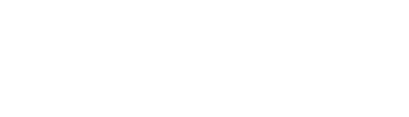

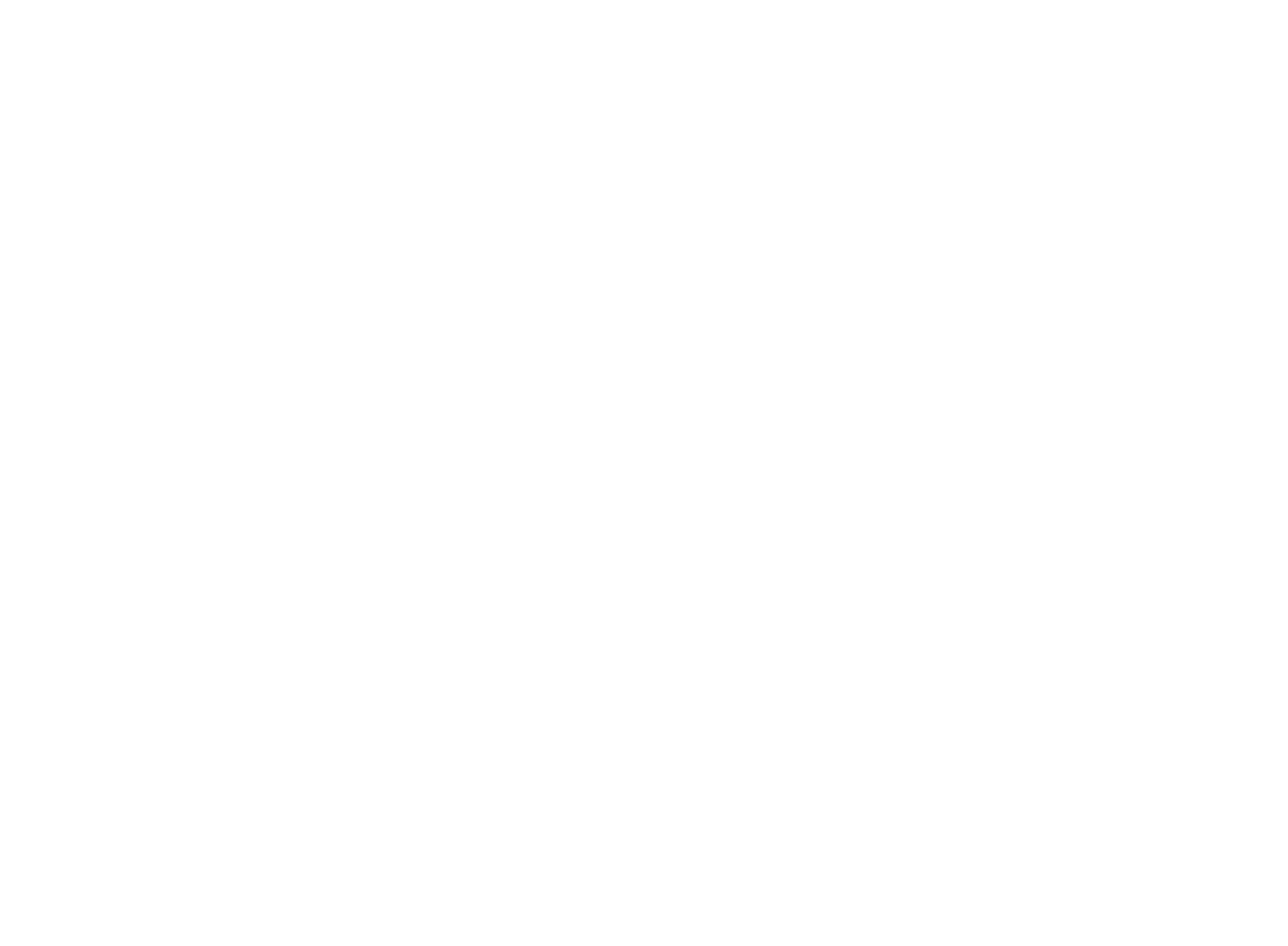


Supplementary Material
Click here to download Supplementary Material: TableS2.pdf

Supplementary Material
Click here to download Supplementary Material: TableS2.pdf

Click here to download Supplementary Material: Tables2.pdf . 
Supplementary Material
Click here to download Supplementary Material: TableS3.pdf

Supplementary Material
Click here to download Supplementary Material: TableS3.pdf

Click here to download Supplementary Material: TableS3.pdf

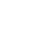

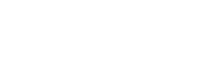

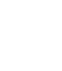

(a)

ppleme .

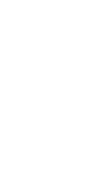

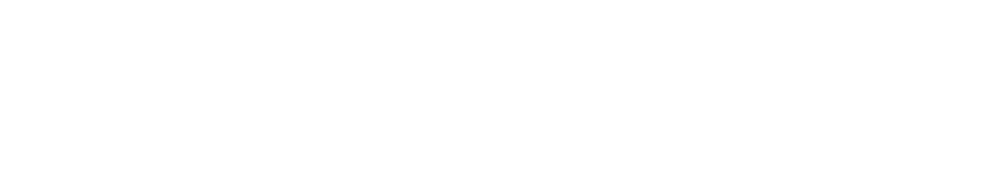
列 
Supplementary Material
Click here to download Supplementary Material: TableS4.pdf

Supplementary Material
Click here to download Supplementary Material: TableS4.pdf

Click here to download Supplementary Material: Tables4.pdf

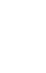

(1)

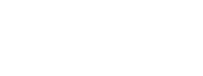

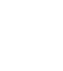

pplementary Material: TableS4.pdf

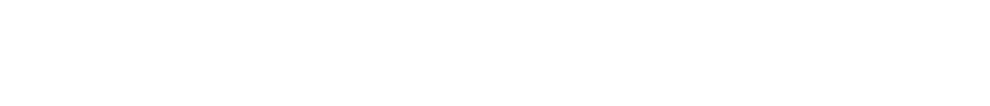

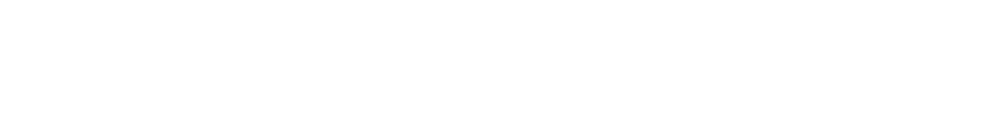

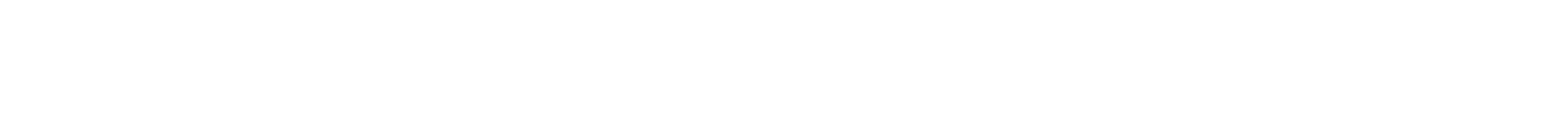
-

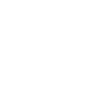

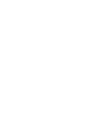

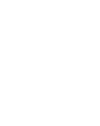

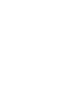

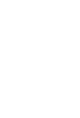

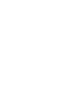

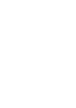

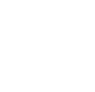

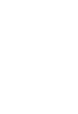
r 
Supplementary Material
Click here to download Supplementary Material: TableS5.pdf

Supplementary Material
Click here to download Supplementary Material: TableS5.pdf

(n)

Click here to download Supplementary Material: Tables5.pdf

Click here to download Supplementary Material: TableS5.pdf

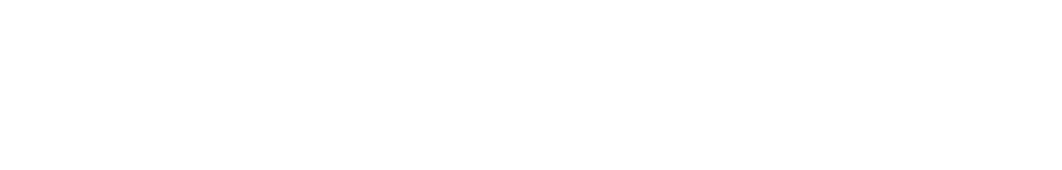

(1)

(1)

(1)

(1)

(1)

(1)

(1)

(1)

.

.

.

.

.

.

.

.

.

.

. 
Click here to download Supplementary Material: TableS6.pdf

Supplementary Material
Click here to download S

Click here to download Supplementary Material: TableS6.pdf

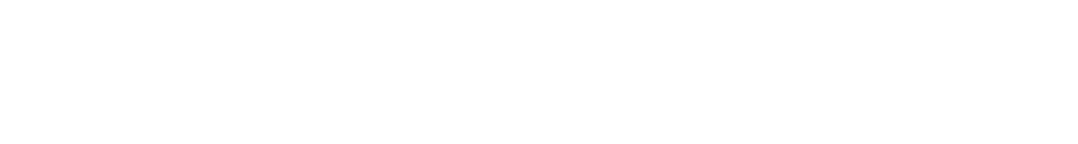

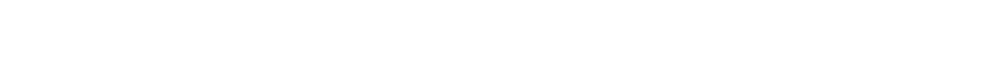

(1)

(1)

(1)

(1)

(1)

(1)

(1)

.

(1)

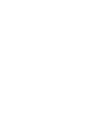

(n)

.

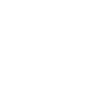

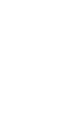

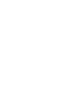

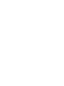

.

-

.

-

.

.

.

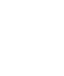

. 
Click here to download Supplementary Material: Tables7.pdf

Supplementary Material
Click here to download S 
Supplementary Material
Click here to download Supplementary Material: TableS8.pdf

Supplementary Material
Click here to download Supplementary Material: TableS8.pdf

(n)

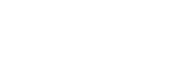

(a)

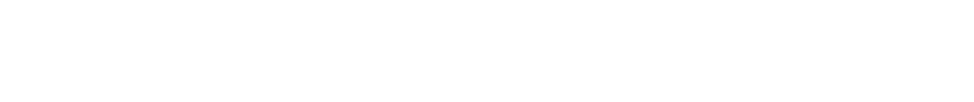

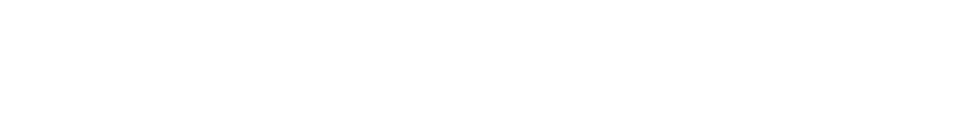

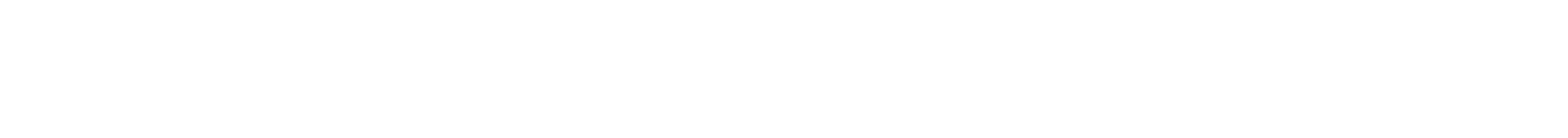
. -

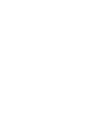
(n)

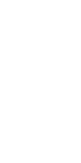

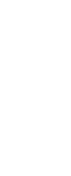

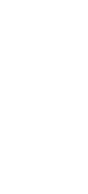

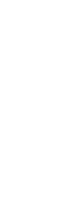

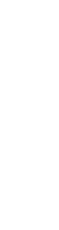
(1) (1) (1) (1) (1) (1) (1) . . . .

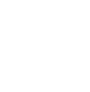

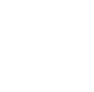

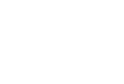

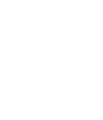

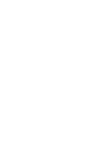

